\title{
IV. Vorgeschichte und Initiierung des Novemberpogroms
}

\section{Antijüdische Maßnahmen in Berlin im Frühsommer 1938}

Aggressive Kampagnen und Gewalt gegen Juden sowie ihre Entrechtung waren elementare Bestandteile von Ideologie und Herrschaftspraxis der Nationalsozialisten und variierten aufgrund sich ändernder Interessen oder taktischer Überlegungen immer wieder. Durch Diskriminierung und finanziellen Druck forcierten die Nationalsozialisten seit 1933 die jüdische Emigration, nicht allein aus ideologischen Motiven, sondern auch, um sich durch Enteignungen, Notveräußerungen und Sonderabgaben am jüdischen Vermögen zu bereichern. Ende 1937 war das Judentum im Deutschen Reich als ökonomischer Faktor weitgehend ausgeschaltet, dennoch stagnierte die jüdische Auswanderung zum Mißfallen der Nationalsozialisten infolge einer rigider werdenden Einwanderungspolitik der Nachbarstaaten und der fortschreitenden Verarmung der jüdischen Bevölkerung und ihrer Institutionen. Das NS-Regime hatte sich also, wie ihm 1938 bewußt wurde, mit seiner Judenpolitik in eine „Sackgasse“1 begeben. Verschärfte Gewalt, die ohnehin bereits an vielen Orten eingesetzt hatte, ${ }^{2}$ sollte den Weg aus ihr bahnen. Zudem fiel nun die Rücksichtnahme auf ausländische Handelspartner weg, da die deutschen Außenhandelsbeziehungen auf ein Minimum gesunken waren. ${ }^{3}$ Goebbels überliefert, Hitler sei Ende November 1937 „fest entschlossen“ gewesen, die Juden aus dem Deutschen Reich und aus Europa zu entfernen (TG, 30.11.1937).

Zweifellos hatten die nationalsozialistische Machtübernahme in Österreich und die Annexion des Nachbarstaates, in deren Folge jüdische Menschen - oder solche, die dafür gehalten wurden - hemmungslos verfolgt, beraubt und mißhandelt wurden, eine radikalisierende Wirkung auf die „Judenpolitik“ und die lokale antisemitische Gewalt des Altreiches. ${ }^{4}$ Schon Stunden vor dem „Anschluß“ begannen willkürliche Verfolgungen von Juden, wenig danach Plünderungen jüdischer Wohnungen und wilde „Arisierungen“" 5 Etwa 200000 Juden waren den Verfol-

1 Wildt, Volksgemeinschaft, 2007, S.310; ders., Judenpolitik des SD, S.57 und Dok.29, S. 186; Gruner, NS-Judenverfolgung und Kommunen, S. 102.

2 Vgl. Wildt, Volksgemeinschaft, 2007.

3 Longerich, Politik, S. 155, 170; Kropat, „Reichskristallnacht“, S. 27.

4 So auch Friedländer, Das Dritte Reich und die Juden, Bd.I, S.262-268; Longerich, Politik, S. 164f.; Longerich, Befehl, S.58f.; Kropat, „Reichskristallnacht“, S. 29-36; Wildt, Judenpolitik des SD, S. 52-54; Wildt, Volksgemeinschaft, 2007, S.301-304; Wildt, Volksgemeinschaft, 2008, S.79-81; Krausnick, Judenverfolgung, S.586; Graml, Reichskristallnacht, S. 169f.; Herbert, Best, S.212f.; Botz, Nationalsozialismus in Wien, S. 126-136; VEJ, Bd.2, ab Dok. 15.

5 Rosenkranz, Entrechtung, S.376-396. 
gungen in Österreich ausgesetzt. ${ }^{6}$ Die Selbstmordrate stieg unter der jüdischen Bevölkerung in Wien, was Goebbels im Tagebuch festhielt, aber vor österreichischen Parteigenossen als Erfindung ausländischer Journalisten darstellte. ${ }^{7}$ Noch Ende März setzen die ersten Massendeportationen von Juden und politischen Repräsentanten aus Österreich in das Konzentrationslager Dachau oder in benachbarte Grenzgebiete ein. ${ }^{8}$

Am Vormittag des 13. März 1938, während des beginnenden Einmarsches der Wehrmacht in Österreich, notierte Goebbels, auf die Presselandschaft in Wien bezugnehmend, in sein Tagebuch: „Die Juden sind größtenteils geflüchtet“ (TG, 13.3. 1938). Nur eine Woche später sprach Goebbels mit Hitler über die Situation in Wien und insbesondere über die dort lebenden Juden, die sie nun aus Wien „herausdrücken“ (TG, 20.3.1938) wollten. Für Goebbels war es vermutlich eine Frage der „Ehre“ als Berliner Gauleiter, daß die Reichshauptstadt bei der Vertreibung der Juden im Vergleich zu Wien nicht nachstehen sollte. ${ }^{9}$ Bis Ende 1937 waren von den ca. 160000 Berliner Juden nicht mehr als ein Drittel emigriert. ${ }^{10}$ Am Tag der Volksabstimmung über den „Anschluß“ Österreichs am 10.April 1938 teilte Hitler Goebbels beim Frühstück mit, daß er „die Juden ganz aus Deutschland herausdrängen“ wolle (TG, 11.4.1938). Keine zwei Wochen später trugen Goebbels und der Berliner Polizeipräsident Graf Helldorf Hitler ihre gemeinsamen Pläne vor, wie sie „Berlin den Charakter eines Judenparadieses“ zu nehmen beabsichtigten (TG, 23.4.1938). Hitler, der Goebbels zufolge die Juden „allmählich alle abschieben“ wollte, war sofort „einverstanden“, wünschte aber, die Aktion „erst nach seiner Italienreise“ zu beginnen. Geplant war unter anderem folgendes, wie Goebbels überliefert: „Judenlokale werden ausgekämmt. Juden bekommen dann ein Schwimmbad, ein paar Kinos und Lokale zugewiesen. Sonst Zutritt verboten. [...] Jüdische Geschäfte werden als solche gekennzeichnet. Jedenfalls gehen wir jetzt radikaler vor“ (TG, 23.4.1938). Die „Kennzeichnung“ jüdischer Geschäfte in Berlin setzte jedoch schon ab dem 1. Mai ein, noch bevor Hitler seinen großangelegten Staatsbesuch bei Mussolini antrat. ${ }^{11}$ Einzelne Berliner Ortsgruppen hatten damit begonnen, jüdische Geschäfte dadurch zu „kennzeichnen“, daß sie an den Schaufensterscheiben antisemitische Parolen anbrachten oder kurzerhand die Scheiben einschlugen. Bei diesen Übergriffen handelte es sich wahrscheinlich

${ }^{6}$ Gruner, Denkschrift, S. 307.

${ }^{7}$ Im Tagebuch hatte Goebbels geschrieben: „Viele jüdische Selbstmorde in Wien“ (TG, 23.3.1938); anläßlich einer Rede vor „alten Kämpfern“ in Österreich hatte Goebbels, einem Bericht des britischen Diplomaten Mack zufolge, am 29.3.1938 geäußert, „that the persecutions and suicides reported in the foreign Press were, as usual, inventions of democratic journalism; but the Jews were talkers and not workers and the Jewish problem would have to be solved“. Telegramm von W. H. B. Mack an das britische Außenministerium, 30.3./1.4.1938, Nr.35, PRO, FO 371/21749; vgl. auch VEJ, Bd.2, Dok.31.

${ }^{8}$ Neugebauer, Österreichertransport, S.17-30; Longerich, Politik, S.164f.; Herbert, Best, S. 213.

${ }^{9}$ So auch Longerich, Politik, S. 174.

$10 \mathrm{Vgl}$. Gruner, Judenverfolgung in Berlin, S.94f.

11 Dirks, „Juni-Aktion“, S. 34. 
nicht um eine zentrale, d.h. von der Berliner Gauleitung organisierte Aktion, ${ }^{12}$ denn erstens war Goebbels zu dieser Zeit mit Hitler in Italien (TG,3.-11.5. 1938), und zweitens hätte sich wohl niemand in der Gauleitung über Hitlers Befehl hinweggesetzt, mit antisemitischen Maßnahmen bis zu seiner Rückkehr zu warten (TG, 23.4.1938).

Helldorf hatte während der Abwesenheit der NS-Führung in Goebbels' Auftrag eine „Denkschrift über die Behandlung der Juden in der Reichshauptstadt auf allen Gebieten des öffentlichen Lebens" ausarbeiten lassen, deren Inhalte die vom NS-Regime „schließlich erreichte Diskriminierungspraxis noch übertrafen“. ${ }^{13}$ Ziel von Goebbels und Helldorf und Thema dieser Denkschrift war, „die Juden aus der Wirtschaft und aus dem Kulturleben, überhaupt aus dem öffentlichen Leben herauszudrücken“ (TG, 25.5.1938). Am 24. Mai hat Goebbels die Denkschrift Helldorfs, ${ }^{14}$ die später vom Sicherheitshauptamt noch erweitert wurde, „durchstudiert" (TG, 25.5.1938). ${ }^{15}$ Vermutlich war Goebbels mit dieser Ausarbeitung nicht vollauf zufrieden, da sie hinter seinen Forderungen zurückblieb; er erwähnte sie jedenfalls in seinen Tagebüchern nach dem 25. Mai 1938 nie wieder. Goebbels wollte Juden eigene Schwimmbäder, Kinos und Lokale zuteilen und ihnen zu allen anderen derartigen Vergnügungsorten den Zutritt verbieten. In der Denkschrift wurden diese Maßnahmen dagegen als kaum durchführbar dargestellt, denn, so wurde darin argumentiert, wenn man beispielsweise jüdische Gemeinden dazu drängen würde, ein jüdisches Kino einzurichten, so würden hier „naturgemäß nur die Juden“ erfaßt, ,die der jüdischen Religionsgemeinschaft angehören", die anderen jedoch nicht. ${ }^{16}$ Ein Besuchsverbot eines nichtjüdischen Theaters oder Kinos für Juden ließe sich, nach Einschätzung der Autoren der Denkschrift, kaum durchführen, „da im Einzelfalle der Jude nicht ohne weiteres zu erkennen ist. Andererseits würden voraussichtlich in vielen Fällen jüdisch aussehende Theaterbesucher zurückgewiesen werden, bei denen sich gegebenenfalls später herausstellen würde, daß es sich um Nichtjuden oder Ausländer handelt". Es bestehe, so hieß es weiter, daher „nur die Möglichkeit“, die Theater- oder Kinobesitzer zu veranlassen, ihre Theater oder „Kinos mit der Aufschrift, Juden unerwünscht ${ }^{\text {zu }}$ kennzeichnen ". 17 Ähnliches sollte der Denkschrift zufolge für Gaststätten gelten: jüdische Inhaber sollten ein Schild mit der Aufschrift „Jüdische Gaststätte - Zutritt nur für Juden“, nichtjüdische Inhaber sollten ein Schild mit dem Schriftzug „Juden unerwünscht“ anbringen müssen. Weiter hieß es in der Denkschrift, daß in den öffentlichen Bädern Berlins Juden bereits ohnehin der Besuch verboten sei, in Privatbädern ließe sich durch eine Anordnung des Polizeipräsidenten eine zeitliche Trennung von Juden und Nichtjuden erreichen. ${ }^{18}$ Der einzige Gesichtspunkt,

12 So auch Longerich, Politik, S. 174.

13 Ebenda, S. 172.

${ }^{14}$ Gruner, Denkschrift, S.308, der diese im Original 61 Seiten umfassende Denkschrift edierte, nennt als Autor einen „untergeordneten Beamten“ der Staatspolizeileitstelle Berlin.

${ }^{15}$ Longerich, Politik, S. 174.

${ }^{16}$ Gruner, Denkschrift, S. 320 .

17 Ebenda, S. 332.

18 Ebenda, S.333f. 
der sich in der Denkschrift so niederschlug, wie Goebbels ihn gefordert hatte, war die Kennzeichnungspflicht jüdischer Betriebe. Unter der Überschrift „Die Kennzeichnung der Geschäfte nach der Rassezugehörigkeit des Inhabers“ hieß es: „Eine Kennzeichnung der Geschäfte in der Reichshauptstadt ist dringend erforderlich “. 19 Die Denkschrift wurde den radikalen Wünschen Goebbels' kaum gerecht, aber dennoch billigte er sie. ${ }^{20}$

Als Goebbels am 29. Mai Hitler das „Judenprogramm für Berlin“ vortrug, war dieser "ganz einverstanden“ (TG,30.5.1938). Am nächsten Tag übermittelte Goebbels Helldorf die Zustimmung Hitlers: „Ich weise Helldorff [!] an, nun unser Berliner Antijudenprogramm in Angriff zu nehmen" (TG, 31.5.1938). Daraufhin ließ Helldorf am 31. Mai in einem Café am Kurfürstendamm eine Razzia veranstalten und das gesamte Publikum festnehmen, und zwar 339 hauptsächlich jüdische Personen. ${ }^{21}$ Im „Völkischen Beobachter“ hieß es hierzu zwei Tage später, es seien „verbrecherisch[e] Elemente, insbesondere Rauschgifthändler, Devisenschieber usw. “ verhaftet worden. ${ }^{22}$ Daß es sich hierbei keineswegs um eine Jagd nach Verbrechern handelte, belegt eindeutig ein Tagebucheintrag von Goebbels: „Helldorff [!] hat unserem Plan entsprechend ca. 300 Juden verhaftet. Ist dann von Berlin weggefahren, und sein Stellvertreter hat sie alle bis auf 6 wieder laufen lassen. Nur die rein Kriminellen festgehalten“ (TG, 2.6.1938). Goebbels war über diesen Fehlschlag ungemein wütend: „Ich schlage Krach wie nie. Helldorff [!] wird sofort zurückzitiert und bekommt einen furchtbaren Anschiß. Mit diesen Juristen im Polizeipräsidium kann man garnichts [!] anfangen. Nun aber nehme ich die Sache in die Hand“ (TG, 2.6.1938). Angesichts der Desavouierung von Goebbels' Plänen, d.h. der Freilassung der Mehrzahl der jüdischen Personen, die bislang nicht bekannt war, ist nun auch erstmals erklärbar, wieso Goebbels einen Tag später in sein Tagebuch schrieb, „die ganze Aktion“ sei „vollkommen versiebt“ (TG, 3.6.1938). ${ }^{23}$ Goebbels schärfte Helldorf an den folgenden Tagen ein, was er zu tun habe, um dem „Ziel: Herausdrückung der Juden aus Berlin“ (TG, 4.6. 1938), näher zu kommen. Nach diesem ersten Fehlschlag wandte sich Goebbels nun direkt an die Polizeibeamten, um ihnen die Richtlinien ihres Handelns vorzugeben: „Vor 300 Polizeioffizieren in Berlin über die Judenfrage gesprochen. Ich putsche richtig auf. Gegen jede Sentimentalität. Nicht Gesetz ist die Parole, sondern Schikane. Die Juden müssen aus Berlin heraus. Die Polizei wird mir dabei helfen“ (TG, 11.6.1938). Kurz darauf wurde die Verhaftung einer größeren Anzahl an Juden auch durch andere Maßnahmen legalisiert.

Zwischen dem 13. und 18. Juni 1938 wurde im gesamten Reichsgebiet die sogenannte „Aktion Arbeitsscheu Reich“ gegen „Asoziale“ (beispielsweise Land-

19 Ebenda, S. 326.

${ }^{20}$ Vgl. Longerich, Politik, S. 174.

${ }^{21}$ Dirks, „Juni-Aktion“, S.37. Longerich, Politik, S.174f., der sich auf Akten des Staatspolizeiamts Berlin stützt, beziffert die verhafteten Juden auf 300 Personen.

22 VB, 2.6.1938, Nr.153, S. 4.

${ }^{23}$ Longerich, Politik, S.175, der den Tagebucheintrag vom 2.6.1938 nicht, sondern nur diejenigen der folgenden Tage kannte, nahm an, Goebbels sei über diese Aktion unzufrieden gewesen, weil sie „ihm nicht weit genug gegangen“ sei, weil in Goebbels' Augen also zu wenig Juden verhaftet worden seien. 
streicher, Bettler, „Zigeuner“, Zuhälter und Personen mit zahlreichen Vorstrafen) durchgeführt, bei der mehrere tausend Menschen verhaftet und in Konzentrationslager eingewiesen wurden. ${ }^{24}$ Die beiden Hauptziele dieser Maßnahme waren die Nutzung der Arbeitskraft der Betroffenen für den Vierjahresplan und die Abschreckung derjenigen, die sich eventuell der noch einzuführenden zivilen Dienstpflicht (22. Juni 1938) widersetzen könnten. ${ }^{25}$ Hitlers Haß auf „asoziale Elemente“ war extrem ausgeprägt; Goebbels überliefert Anfang 1937, daß Hitler diese „ausradiert" sehen wollte, und zwar in „einem Krieg und Zwangsarbeitslagern“ (TG, 22.2.1937). Nachweislich auf Anordnung Hitlers wurde diese Aktion gegen „Asoziale“ auf Juden ausgedehnt. ${ }^{26}$ Für die Verhaftung von Juden im gesamten Reichsgebiet galten aber andere Kriterien als für die der „Asozialen“; im Falle der Juden genügte eine vollzogene oder angedrohte Gefängnisstrafe von mehr als einem Monat für eine Verhaftung im Rahmen der Aktion gegen „Asoziale“. Die Festnahme der Juden war auch anders motiviert: Hier standen nicht volkswirtschaftliche Aspekte im Vordergrund, sondern die Demütigung, die wiederum die Auswanderungsbereitschaft erhöhen sollte. ${ }^{27}$ In zahlreichen Fällen richtete sich die Aktion aber auch gegen Juden, denen man keine Gesetzesübertretung nachweisen konnte. ${ }^{28}$ Mehreren tausend Juden, die am 16. Juni in Berlin bei einer großen Verhaftungswelle festgenommen wurden, warf man pauschal „organisierten Rauschgifthandel“" vor. ${ }^{29}$ Offensichtlich zufrieden über die vielen Festnahmen notierte Goebbels in sein Tagebuch: „Helldorff [!] geht jetzt radikal in der Judenfrage vor. Die Partei hilft ihm dabei. Viele Verhaftungen. [...] Die Polizei hat meine Anweisungen verstanden. Wir werden Berlin judenrein machen. Ich lasse nun nicht mehr locker. Unser Weg ist der richtige“ (TG, 19.6.1938).

Die vielen Razzien und Verhaftungen, von denen auch Ausländer betroffen waren, entgingen der Bevölkerung nicht. Die Exil-SPD schilderte sie in ihren Berichten, und auch in ausländischen Zeitungen erschienen ausführliche Artikel über diese Aktion. ${ }^{30}$ Goebbels vermerkte die kritische ausländische Berichterstattung und die nationalsozialistischen Gegenmaßnahmen in seinem Tagebuch: „Die Auslandspresse tobt“ (TG, 19.6.1938). „Den verleumderischen Auslandsjournalisten lasse ich mit Ausweisung drohen" (TG, 21.6.1938). In den Augen der Nationalsozialisten handelte es sich um eine Verleumdung, wenn in Zeitungen antisemitische oder politische Motive genannt wurden, denn die Verhaftungsaktion wurde

${ }^{24}$ Vgl. Schnellbrief Heydrichs, 1.6.1938, in: VEJ, Bd.2, Dok.39; Ayaß, „Asoziale“, S. 1, 57f., 62 f.; Longerich, Politik, S. 176; Herbert, Best, S.212; Dirks, „Juni-Aktion“, S.33f.

${ }^{25}$ Longerich, Politik, S. 176; Herbert, Best, S. 213.

${ }^{26}$ Longerich, Politik, S. 177; Herbert, Best, S. 213.

${ }^{27}$ Herbert, Best, S.212f.

${ }^{28}$ Vgl. Longerich, Politik, S. 178.

${ }^{29}$ Dirks, „Juni-Aktion“, S.35. Die Anzahl der im Mai/Juni verhafteten Juden wird unterschiedlich beziffert: 1500 im Juni für das gesamte Reichsgebiet: Friedländer, Das Dritte Reich und die Juden, Bd.I, S.282; Dirks, „Juni-Aktion“, S.33; Wildt, Judenpolitik des SD, S. 56; Wildt, Hans Reichmann, S. 75; Kropat, „Reichskristallnacht“, S. 51; Barkai, „Schicksalsjahr 1938“, S. 114; weit über 2500 bei: Gruner, Judenverfolgung in Berlin, S.51; im Mai 1900 und im Juni 1500 Juden bei: Herbert, Best, S.213; Longerich, Politik, S.178, schätzt, daß im Juni allein in Berlin 1000-2000 Juden verhaftet wurden.

${ }^{30}$ Deutschland-Berichte (Sopade), Bd.5, S.755-760. 
vorgeblich „im Rahmen des normalen polizeilichen Fahndungsdienstes“ durchgeführt, um „eine größere Anzahl von asozialen und kriminellen Elementen“ zu erfassen - und nicht etwa „aus politischen Gründen“.31

Parallel zu den polizeilichen Schikanen und Festnahmen hatte die nationalsozialistische Partei ihre im Mai noch vereinzelten Übergriffe auf jüdische Geschäfte im großen Stil Mitte Juni ausgeweitet. Bis Ende Juni war beinahe jedes jüdische Geschäft in Berlin und in einigen anderen Städten durch Schmierereien oder Beschädigungen von Parteigenossen "gekennzeichnet" worden. ${ }^{32}$ In einem SD-Bericht wurde als Urheber dieser Aktion „entweder die Gauleitung Berlin oder der Reichspropagandaminister" vermutet. ${ }^{33}$ Aus den Goebbels-Tagebüchern läßt sich nicht direkt erkennen, daß Goebbels Anstifter dieser Partei-Aktivitäten war. Deutlich wird aber, daß Goebbels auf die Vorgänge Einfluß hatte und diese billigte: „Unsere Pgn. gehen auch etwas scharf heran. Ich bremse da ein wenig. Im Übrigen aber lasse ich der Sache ihren Lauf" (TG,21.6.1938). Als die Situation am 20. und 21. Juni 1938 eskalierte und es zu Zerstörungen in größerem Ausmaß und zu Plünderungen ${ }^{34} \mathrm{kam}$, für die Goebbels ausgerechnet „Zigeuner und andere lichtscheue Elemente“ (TG, 22.6.1938) verantwortlich machte, wies er Helldorf die Schuld dafür zu: „Die Partei hat - wahrscheinlich auf Anregung von Helldorff [!] - die Judengeschäfte beschmiert. [...] Helldorff [!] hat meine Befehle direkt ins Gegenteil verkehrt: ich hatte gesagt, Polizei handelt mit legalem Gesicht, Partei macht Zuschauer. Das Umgekehrte ist nun der Fall“ (TG, 22.6.1938). Die Verantwortung Helldorfs für diese Eskalation erscheint unwahrscheinlich, zum einen, weil Goebbels selbst die Polizei angewiesen hatte, auch nicht-legale Möglichkeiten auszuschöpfen („Nicht Gesetz ist die Parole, sondern Schikane“, TG, 11.6.1938), und zum anderen, weil Helldorf als Polizeipräsident und SA-Führer keine Weisungsbefugnis gegenüber der Partei, sondern allenfalls gegenüber der SA hatte. Zwei Tage später beschuldigte Goebbels einen „Polizeimajor“ und einen „Kreisleiter" (TG, 24.6.1938). Wer nun wirklich als Verantwortlicher für den Vandalismus zu gelten hat, läßt sich durch die Tagebücher nicht ermitteln und scheint auch in der Forschung noch keineswegs geklärt. ${ }^{35}$ Einiges spricht allerdings für Goebbels als Urheber auch der pogromartigen Aktionen. Fest steht jedoch, daß Hitler vor allem aus außenpolitischen Rücksichten den Abbruch der Aktionen inmitten der Sudetenkrise verfügt hatte. ${ }^{36}$ Goebbels notierte diesen Befehl Hitlers erstaunlicherweise nicht, obgleich er sicherlich darüber informiert war. Möglicherweise

31 VB, 19.6.1938, zit. nach Longerich, Politik, S. 178.

32 Die Exil-SPD berichtete von solchen Aktionen in Konstanz, Karlsruhe und Worms; Deutschland-Berichte (Sopade), Bd.5, S.750f. Vgl. auch Bericht des US-Botschafters Hugh R. Wilson vom 22.6.1938, in: VEJ, Bd.2, Dok. 47.

33 SD-Bericht, zit. nach Longerich, Politik, S. 178.

${ }^{34}$ Der amerikanische Botschafter in Berlin, Hugh R. Wilson, benannte als Plünderer indirekt Mitglieder der Hitler-Jugend; vgl. Bericht vom 22.6.1938, in: VEJ, Bd.2, Dok.47; vgl. auch Kulka/Jäckel, Die Juden, Dok.331f.

35 Vgl. Longerich, Politik, S.179f.; Friedländer, Das Dritte Reich und die Juden, Bd.I, S.283f.; Kropat, „Reichskristallnacht“, S. $42 \mathrm{f}$.

36 Wildt, Judenpolitik des SD, S.57; Longerich, Politik, S.179f.; Steinweis, Kristallnacht, S. 13. 
betrachtete er diesen als persönliche Niederlage. Am 21. Juni bestellte Goebbels „alle Parteiinstanzen“ zu sich, gab „neue Befehle heraus“ und verfügte, daß von nun an „[a]lle illegalen Handlungen [...] zu unterbleiben“ hätten (TG, 22.6.1938). Am selben Tag führte Goebbels seinem Tagebuch zufolge abends bei einer Sonnwendfeier eine „[r] ücksichtslose Auseinandersetzung mit dem Judentum“, bei der die „Massen“ vor Begeisterung „tob[t]en“ (TG,22.6.1938), und kündigte neue gesetzliche Maßnahmen gegen die Juden an. ${ }^{37}$

Danach ist, wie auch Goebbels notierte, die "Judenaktion [...] abgeflaut" (TG, 24.6.1938). Die Welle der Gewalt und Verhaftungen im Frühsommer 1938 kann in ihrer Bedeutung kaum überschätzt werden, denn viele Maßnahmen, die ab dem 9. November folgen sollten, waren hier bereits - wenn auch in kleinerem Rahmen - erprobt worden: die massenhafte Verhaftung von Juden und ihre Verbringung in Konzentrationslager, die Beschädigung von jüdischen Geschäften und Synagogen bis hin zum Abriß von Synagogen (z. B. die Hauptsynagogen in München und Nürnberg) ${ }^{38}$ und die den Juden auferlegte Pflicht, daß sie „ihre Geschäfte wieder selbst säubern" sollten (TG, 22.6.1938).

Nach dem Verbot weiterer Ausschreitungen gegen jüdische Geschäfte oder Einrichtungen nahm der antisemitische Aktionismus der Behörden in Berlin aber keineswegs ab. Goebbels plante mit Helldorf bereits die nächsten Maßnahmen: „Helldorff [!] will in Berlin ein Judenghetto errichten. Das sollen die reichen Juden selbst bezahlen. Das ist richtig. Ich unterstütze ihn darin“ (TG, 2.7.1938). Helldorf erarbeitete daraufhin einen Katalog mit 76 „Richtlinien für die Behandlung von Juden und Judenangelegenheiten“, den er am 20. Juli 1938 an die ihm nachgeordneten Dienststellen sandte. ${ }^{39}$ Goebbels, der, wie er selbst in sein Tagebuch notiert hatte, Helldorf zu unterstützen versprach, suchte das Gespräch mit Hitler, um sich für neue antisemitische Maßnahmen bei Hitler abzusichern: „Der Führer billigt mein Vorgehen in Berlin. Was die Auslandspresse schreibt, ist unerheblich. Hauptsache ist, daß die Juden heraus[gedrü]ckt werden“ (TG, 25.7. 1938). Zwei Tage später überreichte Helldorf Goebbels seine neuen Richtlinien: „Helldorff [!] überreicht mir eine Aufstellung der in Berlin gegen die Juden getroffenen Maßnahmen. Die sind nun wirklich rigoros und umfassend. Auf diese Weise treiben wir die Juden in absehbarer Zeit aus Berlin heraus“ (TG, 27.7.1938). Die von Helldorf verfügten Bestimmungen sollten Schikanen „im Rahmen der gesetzlichen Vorschriften" regeln. So sollten Juden beispielsweise erhöhte Strafgelder bezahlen, ihre Anträge bei Behörden sollten mit Verzögerung bearbeitet werden, jüdische Kraftfahrzeuge sollten schon bei den geringsten Mängeln eingezogen werden, und jüdische Geschäfte und Gewerbe sollten verschärften Preis-, Hygiene- und Brandschutzkontrollen unterzogen werden. ${ }^{40}$ Helldorf erstattete Goebbels in der Folgezeit mehrmals Bericht über die „Judenaktionen“ und ihre Aus-

${ }^{37}$ Vgl. VB-Artikel über Goebbels' Rede, in: VEJ, Bd.2, Dok. 48, sowie Bericht des US-Botschafters, Hugh R. Wilson, vom 22.6.1938, in: VEJ, Bd.2, Dok. 47.

38 Siehe Honigschnabel, München, S.96-111; VEJ, Bd.2, Dok.40; Zelnhefer, Nürnberg, S. 46-57; Kulka/Jäckel, Die Juden, Dok.342f.

${ }^{39}$ Runderlaß Helldorfs vom 20.7. 1938, in: VEJ, Bd.2, Dok. 68.

${ }^{40}$ Gruner, Judenverfolgung in Berlin, S. 53; Longerich, Politik, S.182f. 
wirkungen auf die Zahl der jüdischen Emigrationen. Ende August schrieb Goebbels in sein Tagebuch, die „weiteren Judenaktionen“ gingen „planmäßig vor sich“, es seien bereits viele Juden „aus Berlin ausgewandert“ und er lasse nun das Vermögen der Berliner Juden verzeichnen (TG, 31.8.1938). ${ }^{41}$ In der ersten Oktoberhälfte notierte Goebbels erneut, die „Judenaktion in Berlin“, zu der auch Beschädigungen von Synagogen gehörten, ${ }^{42}$ verlaufe „planmäßig“, und er äußerte die Hoffnung, daß die Juden „nun allmählich“ aus Berlin abzögen (TG, 12.10.1938).

Auch in Wien wurde im Laufe des Jahres 1938 der Druck auf die jüdische Bevölkerung verstärkt. Seit Mitte Oktober 1938, nach einem weiteren Radikalisierungsschub infolge des Münchener Abkommens vom 29. September 1938, setzten dort - wie auch in anderen Städten des Reichs - ähnliche Ausschreitungen ein, wie die beschriebenen im Frühsommer in Berlin. ${ }^{43}$ In den dem Reich eingegliederten sudetendeutschen Gebieten war die jüdische Bevölkerung auch wegen ihrer überwiegend anti-nationalsozialistischen und damit pro-tschechoslowakischen Haltung noch vor Eintreffen der Wehrmacht wüsten Verfolgungen ausgesetzt. ${ }^{44}$ Der Verbindungsoffizier Henleins zum OKW berichtete, Hitler habe dem Sudetendeutschen Freikorps „3 Tage Jagdfreiheit auf alle mißliebigen Elemente“ zugestanden. ${ }^{45}$ Eine unbekannte Anzahl von Juden wurde sogleich ermordet, viele begingen Selbstmord. Mit Beginn der deutschen Verwaltung wurden Juden wahllos verhaftet, in Konzentrationslager gebracht, ultimativ zur Ausreise gezwungen oder zur tschechischen Grenze transportiert und mit sofortiger Wirkung ausgewiesen. Selbst aus den österreichischen Gauen wurden nun Juden zur Grenze der Tschechoslowakei gebracht. ${ }^{46}$ Hitler ließ im Oktober 1938 prüfen, ob die „Ausweisung der 27000 Juden tschechischer Staatsangehörigkeit aus Wien möglich“ wäre. ${ }^{47}$ Forciert durch den „Anschluß“ Österreichs und die Sudetenkrise wurden wenige Wochen vor dem Pogrom im November 1938 die allgemeinen Diskriminierungen im Reichsgebiet fortgesetzt. Zu diesen Maßnahmen gehörte beispielsweise die Pflicht, Kennkarten zu beantragen, die die Träger eindeutig als Juden identifizierten. Diese Karten waren von nun an bei jedem Behördenverkehr vorzuzeigen oder anzugeben. ${ }^{48} \mathrm{Zu}$ demselben Zweck mußten die polizeilichen Meldebehörden Personenregisterkarten anlegen, die über die „Abstammung“ Auskunft gaben. ${ }^{49}$ Bereits im August 1938 wurde auch verfügt, daß Jüdinnen und Juden ab 1. Januar 1939 ihren Vornamen durch „Sara“ bzw. „Israel“ zu ergänzen

${ }^{41}$ Vgl. Bericht des SD-Hauptamts II 112, Berlin, 8.9.1938, in: Kulka/Jäckel, Die Juden, Dok.346.

42 Longerich, Himmler, S. 422.

${ }^{43}$ Vgl. Kropat, „Reichskristallnacht“, S.35; Longerich, Politik, S. 193; Kulka/Jäckel, Die Juden, Dok. 348, 350f., 353.

${ }^{44}$ Osterloh, Judenverfolgung, S. 186-188.

${ }^{45}$ Krausnick, Tagebücher Groscurth, S. 127. Auch der Generalquartiermeister des Heeres beklagte, daß das Freikorps ,jenseits der Grenze Unfug“ gemacht habe; Wagner, Besetzung der Tschechoslowakei, S.580.

46 Osterloh, Judenverfolgung, S. 198-201.

47 Anonyme Aufzeichnung aus dem A.A., 12.10.1938, in: ADAP, D 4, Dok. 53.

48 2. Bekanntmachung über Kennkartenzwang, 23.7. 1938, RGBl. 1938, Teil I, S. 922.

${ }^{49}$ Reichsmeldeordnung, Runderlaß des Reichsinnenministers, 26.8.1938, in: Walk, Sonderrecht, S.239. 
hatten. ${ }^{50}$ Im Oktober 1938 wurden alle Reisepässe von deutschen Juden durch eine Verordnung für ungültig erklärt, wenn sie nicht das nun obligatorische, eingestempelte „J“ enthielten ${ }^{51}$ - eine, wie noch zu zeigen sein wird, folgenreiche Maßnahme.

\section{Beginn einer antisemitischen Gesetzgebung in Italien}

Ein weiteres Moment, das die Radikalisierung der nationalsozialistischen „Judenpolitik“ im Jahre 1938 verstärkte und lange Jahre kaum Beachtung fand, bestand in den antisemitischen Maßnahmen und Verordnungen der faschistischen Regierung Italiens des Jahres 1938. Diese erfolgten nicht auf Druck Berlins und kamen daher auch für das NS-Regime einigermaßen überraschend, ${ }^{52}$ obgleich Mussolini bereits 1936 einen deutlichen Kurswechsel im Verhältnis zum Judentum eingeleitet hatte. Diese „antisemitische Wende“ wird in der Forschung in der Regel mit dem 1935 begonnenen Krieg gegen Abessinien begründet. ${ }^{53}$ Das erste rassistische Gesetz Italiens vom 19.April 1937 war erlassen worden, um die befürchtete Rassenvermischung italienischer Soldaten mit einheimischen Frauen im Kolonialraum zu unterbinden. Sexueller Verkehr zwischen einem Italiener und einer afrikanischen Person oder einem Angehörigen eines anderen sogenannten primitiven Volkes wurde dort mit ein bis fünf Jahren Gefängnis bestraft. ${ }^{54}$

Etwa zur gleichen Zeit setzte eine antisemitische Kampagne ein, ${ }^{55}$ doch richtete sie sich in erster Linie gegen das internationale Judentum. Im Februar 1938 hatte sich Goebbels noch enttäuscht gezeigt, daß sich „Rom“ gegen den „Rassenantisemitismus“ gewandt und von „seinen ,loyalen Juden“" gesprochen habe (TG, 16.2. 1938). ${ }^{56}$ Um so größer war Goebbels’ Freude über die Veröffentlichung eines rassenpolitischen Manifests am 14. Juli 1938, das im Auftrag Mussolinis erarbeitet worden war. ${ }^{57}$ Darin wurde das jüdische Volk nun rassisch definiert. Goebbels notierte hierüber in sein Tagebuch: „Italien legt ein fast offizielles Manifest zur Rassenfrage nieder. Mit ganz klaren Entscheidungen zu unseren Grundsätzen. Gegen die Juden. Nordisch - arisch. Gegen Afrika. Ein großer Triumph für uns. Die westeuropäische Presse wertet das auch so. Mussolini scheint nun weitere Konsequenzen ziehen zu wollen“ (TG, 16.7.1938). Dieses Manifest vom 14. Juli 1938 umfaßte folgende zehn Punkte: 1. Feststellung der Existenz menschlicher Rassen;

${ }^{50}$ Erlaß des Reichsinnenministers, 18.8.1938, in: Walk, Sonderrecht, S. 237.

${ }^{51}$ Verordnung über Reisepässe von Juden, 5.10.1938, RGBl. 1938, Teil I, S.1342. Zum Anlaß dieser Verordnung siehe ADAP, D 5, Dok. 642-644.

52 Pommerin, Rassenpolitische Differenzen, S. 647; Collotti, Die Historiker, S. 59-77.

${ }^{53}$ Schlemmer/Woller, Faschismus und die Juden, S. 174-179; Wetzel, Mythos, S. 61.

${ }^{54}$ Regio Decreto Legge, Nr.880, 19.4.1937, in: Gazzetta ufficiale del Regno d'Italia, 24.6.1937; Collotti, Il fascismo, S.37.

55 Collotti, Il fascismo, S. 40-57; Martelli, La propaganda, S. 18-21.

${ }^{56}$ Goebbels bezog sich wahrscheinlich auf einen Artikel im Regierungsblatt „L'Informazione Diplomatica", Nr. 14, 16.2.1938; vgl. Collotti, Il fascismo, S.58f.; Martelli, La propaganda, S. 20 f.

${ }^{57}$ Schlemmer/Woller, Faschismus und die Juden, S. 179; Martelli, La propaganda, S.23-25; Collotti, Il fascismo, S. 60-62. 
2. Unterscheidung in "große“ und angeblich minderwertige Rassen; 3. Biologische Definition der Rasse; 4. Feststellung des „arischen“ Ursprungs des italienischen Volkes und seiner Kultur; 5. „Rassereinheit“ des italienischen Volkes seit der Einwanderung der Langobarden; 6. Existenz einer reinen „razza italiana“; 7. Proklamation der Italiener als rassistisch; 8. Notwendigkeit einer Differenzierung zwischen westlichen Mittelmeerbewohnern und den östlichen bzw. den Afrikanern; 9. „Die Juden gehören nicht zur italienischen Rasse“; 10. Forderung, die „rein europäischen physischen und psychologischen Eigenschaften der Italiener" zu wahren, die „Rassenmischung“ zu untersagen. ${ }^{58}$

Die Nationalsozialisten fühlten sich in ihrer Politik gegen das Judentum nun also bestätigt, was im Falle Mussolinis besonders bedeutsam war, weil er von den Nationalsozialisten lange Zeit als „Vorbild“ angesehen wurde. ${ }^{59}$ Im Bereich der Judenverfolgung waren allerdings die Nationalsozialisten Vorreiter, was Goebbels und Hitler besonders befriedigte. Nach einer Besprechung mit Hitler über die „Judenfrage“ hielt Goebbels im Tagebuch fest: „Auch Italien schwenkt da in unsere Linie ein. Mussolini ist von Anlage aus Antisemit. Er konnte das früher nur schwer betätigen. Jetzt hat er uns als Bundesgenossen“ (TG, 25.7.1938). Der zunehmende Antisemitismus der faschistischen Regierung wurde vom Papst mißbilligt, doch Mussolini wies diese Kritik zurück, was Goebbels erfreut zur Kenntnis nahm: „Mussolini gibt dem Papst eine gepfefferte Antwort auf seinen Ausflug in das Gebiet der Rassepolitik. Die war auch fällig und kann uns sehr angenehm sein“ (TG, 1.8.1938). ${ }^{60}$ Am 5.August 1938 bestätigte das Amtsblatt „L'informazione diplomatica“ den antisemitischen Kurs der italienischen Regierung. ${ }^{61}$ Möglicherweise bezog sich Goebbels auf diese Quelle, als er am selben Vormittag die Vorgänge in Italien kommentierte: „Rom zieht jetzt praktische Konsequenzen aus der Rasselehre. Scharfe Verordnungen gegen die ausländischen Juden. ${ }^{62}$ So fängt das an. Nun wird das Weltjudentum Mussolini schon von selbst weitertreiben. Die Juden sind ja so dumm“ (TG, 5.8.1938). Goebbels erwartete also Proteste des jü-

${ }^{58}$ Manifest abgedr. in: De Felice, Storia degli ebrei italiani, Dok.15, S.611f. Siehe auch: Martelli, La propaganda, S.24f.; Collotti, Il fascismo, S.60-62; Wetzel, Mythos, S.62f.; Heiber, Beeinflussung, S.82; Mantelli, Faschismus, S.118f.; Schlemmer/Woller, Faschismus und die Juden, S. $179 \mathrm{f}$.

${ }^{59}$ Kershaw, Hitler, Bd.1, S.230. Goebbels notierte beispielsweise im Frühjahr 1938, daß Mussolini „Gegenstand“ von Hitlers „Bewunderung“ sei; TG, 20.3.1938. Vgl. auch TG, 4.5.1938, 8.5.1938, 10.5.1938.

${ }^{60}$ Der Papst hatte am 28.7.1938 kritisiert, daß Italien auf dem Gebiet des Antisemitismus die Nationalsozialisten zu kopieren versuche. Mussolini dementierte zwei Tage später, daß es sich um eine Nachahmung deutscher Maßnahmen handle. Vgl. Pommerin, Rassenpolitische Differenzen, S.648; Heiber, Beeinflussung, S.82f. Dennoch leistete der Papst letztlich keinen ernsthaften Widerstand gegen die antisemitischen Gesetze; vgl. Mantelli, Faschismus, S. 119; Collotti, Il fascismo, S.98-100; Schlemmer/Woller, Faschismus und die Juden, S. 183f. Vgl. auch einen späteren Tagebucheintrag von Goebbels: „Der Papst schw[i]tzt sich über die italienische Ehegesetzgebung aus. Er will die Rassenfrage darin nicht anerkennen. Aber das wird Mussolini nicht sonderlich interessieren“, TG, 17.11.1938.

${ }^{61}$ L'informazione diplomatica, Nr. 18, 5.8.1938, abgedr. in: De Felice, Storia degli ebrei italiani, Dok. 17, S.615; siehe auch Collotti, Il fascismo, S.68; Mantelli, Faschismus, S. 119.

${ }^{62}$ Am 3.8.1938 wurde ausländischen Juden der Besuch öffentlicher italienischer Schulen und Universitäten verboten; vgl. Heiber, Beeinflussung, S. 83. 
dischen Volkes, was seiner Meinung nach zu noch drastischeren Maßnahmen der faschistischen Regierung führe. Zwei Tage später hielt Goebbels fest: „Mussolini erläßt neue Rassegesetze. Numerus clausus für die Juden. Er hat also Blut geleckt“ (TG, 7.8.1938). Der am 5.August 1938 verkündete „Numerus clausus“ gegen Juden beschränkte die Beschäftigung von Juden im öffentlichen Leben auf ihren proportionalen Anteil am italienischen Gesamtvolk. ${ }^{63}$ Als eine Woche später die „Richtlinien für die italienische Rassepolitik“ herausgegeben wurden, meinte Goebbels: „Mussolini scheint nun Ernst machen zu wollen“ (TG, 14.8.1938).

Am 1./2. September 1938 beschloß der italienische Ministerrat fünf bedeutende antisemitische Maßnahmen, die wenige Tage später Gesetzeskraft erlangten. ${ }^{64}$ Einige davon vermerkte Goebbels in seinem Tagebuch: „Mussolini geht jetzt scharf gegen die Juden vor. Weist ausländische Juden aus und setzt sie als Lehrer ab“ (TG, 3.9.1938). Tatsächlich wurde ausländischen Juden verboten, in Italien bzw. den Kolonien einen festen Wohnsitz zu nehmen; bisher im Königreich lebende ausländische Juden hatten innerhalb von sechs Monaten Italien zu verlassen; entsprechende Einbürgerungen wurden zurückgenommen. Als Jude galt, wessen Eltern beide „jüdischer Rasse“ waren. ${ }^{65}$ Die Tatsache, daß nicht nur jüdischen Lehrern der Unterricht an italienischen Schulen verboten, sondern auch jüdischen Schülern ein Besuch öffentlicher Schulen und Universitäten verwehrt wurde, vermerkte Goebbels erst einen Tag später: „Mussolini schmeißt nun die Juden aus den Schulen und Universitäten heraus“ (TG, 4.9.1938). ${ }^{66}$ Möglicherweise konnte Goebbels die Nachricht über das Verbot des Schulbesuchs jüdischer Schüler zunächst nicht glauben, denn ein solches Gesetz gab es noch nicht einmal im nationalsozialistischen Deutschland. Am Morgen nach der Pogromnacht debattierten die Ratsherren der Stadt München zusammen mit den Beiräten unter Oberbürgermeister Karl Fiehler die mögliche Entfernung jüdischer Schüler aus den städtischen Schulen. Als Ratsherr Josef Beer fragte, „ob wir diese Judenbankerte drin lassen müssen“, ist im Sitzungsprotokoll der folgende Zwischenruf des Ratsherrn Max Zankl vermerkt: „Totschlagen!“67 Zwei Tage später schlug Goebbels auf der Besprechung über die „Judenfrage“ bei Göring vor, daß „die Juden absolut aus den deutschen Schulen entfernt werden“.68 Drei Tage danach wurde Goebbels’ Anregung Gesetz. ${ }^{69}$

${ }^{63} \mathrm{Vgl}$. ebenda.

${ }^{64}$ Auf diese Gesetze wiesen in der deutschsprachigen Literatur u. a. bereits Heiber, Beeinflussung, S. 84, und Mantelli, Faschismus, S.119f., hin.

${ }^{65}$ Regio Decreto Legge, Nr. 1381, 7.9.1938, in: Gazzetta ufficiale del Regno d'Italia, Nr. 208, 12.9.1938.

${ }^{66}$ Regio Decreto Legge, Nr. 1390, 5.9.1938, in: Gazzetta ufficiale del Regno d'Italia, Nr. 209, 13.9.1938. Für Studenten waren Ausnahmen möglich.

${ }^{67}$ Niederschrift, 37. Sitzung der Beiräte für Verwaltungs-, Finanz- und Baufragen der Hauptstadt der Bewegung, 10.11.1938, StadtAM, Ratssitzungsprotokolle, Jg. 1938, Nr.711/4, Tagesordnungspunkt 12.

${ }^{68}$ Stenographische Niederschrift der Besprechung über die Judenfrage bei Göring, 12.11.1938, in: IMG 28, Dok. 1816-PS, S.499-540, hier S.511; jetzt auch abgedr. in: VEJ, Bd. 2, Dok. 146, S. 408-437, hier S. 417.

${ }^{69}$ Erlaß des Reichsministers für Wissenschaft, Erziehung und Volksbildung, 15.11.1938, in: Walk, Sonderrecht, S. 256. 
Die antijüdischen Verordnungen in Italien hatten, wie auch Goebbels im Tagebuch festhielt, zur Folge, daß Mussolini „maßlos“ in der internationalen Presse „angegriffen“ worden sei, die der Propagandaminister daher als „Judenpresse“ bezeichnete. "Gilt dort schon als Überhitler" (TG,4.9.1938), notierte Goebbels pointiert. Am 6.Oktober 1938 gab der „Große Faschistische Rat“ eine Stellungnahme ${ }^{70}$ zur „Rassenpolitik“ ab, bestätigte die bisherigen Maßnahmen und erließ eine Reihe neuer Bestimmungen, ${ }^{71}$ die in das umfangreiche Sammeldekret zum „Schutz der italienischen Rasse“ vom 17. November $1938^{72}$ eingingen und über die Goebbels in sein Tagebuch schrieb: „Der faschistische Großrat faßt sehr scharfe Entschlüsse in der Rassenfrage, insbesondere gegen die Juden. Die meisten dieser Entschlüsse sind deutschen Gesetzen nachgebildet. Mussolini macht also tabula rasa. Das ist gut so. Er verschafft sich nun auch die Vorteile des Antisemitismus, da die Juden in der Welt ihm sowieso die Nachteile zufügen" (TG, 8. 10.1938).

Goebbels’ Bewunderung fand auch Mussolinis Umgang mit den ausländischen Protesten, für die der Propagandaminister wiederum die Juden verantwortlich machte: „In USA hetzen jetzt die Juden gegen den Faschismus. Aber Mussolini läßt ganz kategorisch mit Repressalien gegen die italienischen Juden drohen. Das wird wohl die Gemüter etwas abkühlen“ (TG,20.10.1938). Eine offene Drohung mit Repressalien gegen das jüdische Volk war auch bei den Nationalsozialisten ein beliebtes Mittel, um Kritik zum Schweigen zu bringen, wenngleich es seit dem April-Boykott von 1933 nicht mehr im großen Stil angewandt worden war.

\section{Die erste Deportation polnischer Juden und das Attentat auf Ernst vom Rath}

Seit Mitte der 30er Jahre bemühte sich die polnische Regierung verstärkt, ethnische und religiöse Minderheiten zur Emigration zu drängen. Ursachen dafür waren eine desolate wirtschaftliche Situation mit hoher Arbeitslosigkeit und ein zunehmender Nationalismus. ${ }^{73}$ Die Auswanderung polnischer Juden scheiterte jedoch an der restriktiven Einwanderungspolitik der Nachbarstaaten, vor allem Deutschlands. Zudem forcierte die deutsche Regierung ihrerseits die Emigration der Juden, die sich auf ihrem Territorium aufhielten, besonders derjenigen, die nicht im Besitz der deutschen Staatsangehörigkeit waren. Die polnische Regie-

${ }^{70}$ Abgedr. in: Collotti, Il fascismo, Dok.1, S.187-190; De Felice, Storia degli ebrei italiani, Dok. 20, S.624-627.

${ }^{71} \mathrm{Zu}$ den neuen Verordnungen gehörte das Verbot von Ehen zwischen Italienern und „Nichtariern“, das Verbot für Juden, größere Betriebe (ab 100 Beschäftigten) zu besitzen oder zu leiten, das Verbot für Juden, Grundstücke über 50 Hektar zu besitzen und der Ausschluß der Juden aus dem Militärdienst. Ausgenommen von diesen Bestimmungen waren Kriegsteilnehmer und die Angehörigen von dekorierten, verwundeten oder gefallenen Kriegsteilnehmern. Vgl. Heiber, Beeinflussung, S.85; Schlemmer/Woller, Faschismus und die Juden, S. 180-182.

72 Regio Decreto Legge, Nr.1728, 17.11.1938, in: Gazzetta ufficiale del Regno d'Italia, Nr.264, 19.11.1938; publiziert bei: De Felice, Storia degli ebrei italiani, Dok.21, S.630635; siehe auch Collotti, Il fascismo, S. 193-197.

${ }^{73}$ Vgl. Tomaszewski, Auftakt, S.39-72; Esch, Politik, S. 131f.; Heiber, Grünspan, S. 139. 
rung fürchtete daher, daß die über 50000 Juden polnischer Staatsangehörigkeit, die in Deutschland lebten, und die etwa 20000 polnischen Juden, die nach dem „Anschluß“ Österreichs Repressalien der Nationalsozialisten ausgesetzt waren, nach Polen zurückkehren könnten. ${ }^{74}$ Am 31. März 1938 beschloß das polnische Parlament ein Gesetz, das die Ausbürgerung polnischer Staatsangehöriger ermöglichte, falls diese im Ausland dem polnischen Staat geschadet hätten oder nach fünfjährigem Aufenthalt im Ausland die Bindung an den polnischen Staat verloren hätten oder trotz Aufforderung nicht nach Polen zurückgekehrt seien. ${ }^{75}$ Diese weit auslegbaren Bestimmungen waren dazu geeignet, eine sehr große Anzahl polnischer Juden auszubürgern, die sich außerhalb der polnischen Grenzen befanden, was auch den Nationalsozialisten bewußt war. ${ }^{76}$ Als nun auch das Deutsche Reich daraufhin begann, polnische Juden bei geringsten Anlässen des Landes zu verweisen, ${ }^{77}$ und als sich im Sommer 1938 abzeichnete, daß Juden polnischer Staatsangehörigkeit im Deutschen Reich immer mehr verarmten, glaubte man im polnischen Innenministerium, unter Zugzwang zu stehen. Am 6.Oktober 1938 wurde eine Verordnung erlassen, die die Überprüfung und Kennzeichnung aller Pässe im Ausland lebender Polen bis zum 30. Oktober 1938 bestimmte - eine direkte Folge der entsprechenden deutschen Maßnahme vom Vortag, die Pässe deutscher Jüdinnen und Juden mit einem „J“ zu stempeln. ${ }^{78}$ Die Betroffenen dieser polnischen Verordnung, die der Verpflichtung zur Kennzeichnung der Pässe nicht nachkamen und keinen Kontrollvermerk vorweisen konnten, durften nicht mehr nach Polen einreisen. ${ }^{79}$ Das Auswärtige Amt gab daraufhin am 26. Oktober 1938 bekannt, daß die ,in Deutschland befindlichen Juden polnischer Staatsangehörigkeit [...] deshalb vorsorglich sofort mit kürzester Frist aus dem Reich verwiesen werden“ sollten; es sei denn, die polnische Regierung würde „von der Durchführung der Verordnung vom 6.Oktober d.J. im Reichsgebiet Abstand“ nehmen oder „die bindende Erklärung “ abgeben, daß die Inhaber polnischer Pässe auch ohne den Prüfungsvermerk die polnische Staatsangehörigkeit behielten. ${ }^{80}$ Die polnische Regierung reagierte mit Beschwichtigungen. ${ }^{81}$ Ein Runderlaß des Reichsführers SS und Chef der deutschen Polizei ordnete daraufhin an, daß alle

${ }^{74}$ Vgl. Maurer, Abschiebung und Attentat, S. 56, 59; Longerich, Politik, S. 195; Esch, Politik, S.132f., 137; Goldberg, Zwangsausweisung, S.973; Heiber, Grünspan, S. 136, 139.

75 Vgl. Tomaszewski, Auftakt, S. 85-91; Esch, Politik, S. 134; Maurer, Abschiebung und Attentat, S.59; Heiber, Grünspan, S. 136.

${ }^{76}$ Vgl. Tomaszewski, Auftakt, S.93f.; siehe auch SD-Bericht für April/Mai 1938, in: Wildt, Judenpolitik des SD, Dok.29, S. 187.

77 Vgl. Tomaszewski, Auftakt, S.96-100; Maurer, Abschiebung und Attentat, S. 60.

78 Verordnung über Reisepässe von Juden, 5.10.1938, RGBl. 1938, Teil I, S. 1342; zum Anlaß siehe ADAP, D 5, Dok.642-644; Tomaszewski, Auftakt, S.73f.

${ }^{79}$ Vgl. Tomaszewski, Auftakt, S.106; Esch, Politik, S.137-139; Maurer, Abschiebung und Attentat, S. 60; Longerich, Politik, S. 197; Heiber, Grünspan, S. 136.

80 Telefonische Weisung des Leiters der Rechtsabteilung im A.A. an die deutsche Botschaft Warschau, 26.10.1938, in: ADAP, D 5, Dok. 84, S. 93.

${ }^{81}$ Der polnische Geschäftsträger sprach gegenüber dem Leiter der politischen Abteilung im A.A., Woermann, von einem „Mißverständnis“. Aufzeichnung Woermanns, 28.10.1938, in: ADAP, D 5, Dok. 89, S.97f. Siehe auch Aide-Mémoire des polnischen Außenministeriums, 27.10.1938, in: ADAP, D 5, Dok. 88, S.97; Tomaszewski, Auftakt, S. 109-112; Esch, Politik, S. 139. 
polnischen Juden das Reichsgebiet bis zum 29. Oktober 1938 zu verlassen hätten. ${ }^{82}$ Nach diesem Erlaß folgte von dieser Behörde die konkrete Anweisung, „daß eine möglichst große Zahl polnischer Juden [...] rechtzeitig vor dem genannten Zeitpunkt über die Grenze nach Polen geschafft" werden sollte. ${ }^{83}$ Da die Verhaftungen und Deportationen nicht in allen Städten zeitgleich einsetzten, konnten sich ihnen, nach Warnungen, einige der Betroffenen entziehen. ${ }^{84}$ Zur Grenze wurden schließlich ca. 18000 polnische Juden gebracht, ca. 12000 gelangten auf polnisches Territorium, die anderen ca. 6000 Menschen irrten tagelang im Niemandsland zwischen den Grenzen umher. ${ }^{85}$

$\mathrm{Zu}$ diesen 12000 Menschen gehörten auch die engsten Verwandten von Herschel Grynszpan, dem Attentäter von Paris. Goebbels notierte weder die Maßnahmen der polnischen Regierung noch die Deportation der polnischen Juden in sein Tagebuch. Angesichts der Bedeutung dieser Aktion verwundert das. Die Tatsache, daß Goebbels das polnische Gesetz vom 31. März und die ministerielle Verordnung nicht erwähnte, könnte daran liegen, daß Goebbels - wenn er die beiden Maßnahmen überhaupt kannte - sich über deren Bedeutung nicht im klaren war, so wie auch das Auswärtige Amt erst wenige Tage vor Ablauf der Frist zum 30. Oktober aktiv wurde. Am 27. Oktober, als im Reichsgebiet begonnen wurde, polnische Juden festzunehmen und in Züge zu verladen, befand sich Goebbels wegen des erzwungenen Endes seiner Affäre mit der tschechischen Schauspielerin Lida Baarova in einem desolaten physischen Zustand, so daß er sich tagsüber „ins Bett“ legte und „18 Stunden hintereinander“ schlief (TG,29.10.1938). Seinem Tagebuch vertraute Goebbels am 29. Oktober, seinem Geburtstag, an, daß sein „einzigster und heißester Wunsch“ wäre, „nichts mehr“ zu „sehen“, zu „hören“ und zu „wissen“ (TG, 29.10.1938). Angesichts dieser Situation scheint es möglich, daß Goebbels die Verschleppung der polnischen Juden zunächst unbekannt blieb, oder daß sie für ihn zu diesem Zeitpunkt zumindest nicht die nötige Relevanz besaß, festgehalten zu werden.

Herschel Grynszpan, ein 17jähriger Jude mit polnischem Paß, der 1921 in Hannover geboren wurde und dort aufgewachsen war, hielt sich wahrscheinlich seit August 1936 in Paris auf, hatte für Frankreich aber keine Aufenthaltsgenehmigung mehr. Zum 15. August 1938 sollte er gemäß einer Ausweisungsverfügung das Land verlassen. Nach Deutschland, wo er bis Juli 1936 gelebt hatte, konnte er nicht zurückkehren, da seit April 1937 seine Wiedereinreisegenehmigung nicht mehr gültig war. Ebensowenig durfte er nach Polen einreisen, da sein Paß im Januar 1938 abgelaufen war. ${ }^{86}$ Herschel Grynszpan befand sich also in einer schwierigen Lage. Am 3. November 1938 erfuhr er durch eine Postkarte seiner Schwester von der Deporta-

82 Runderlaß des RFSSuCdDP vom 26.10.1938, in: Walk, Sonderrecht, S. 247.

${ }^{83}$ Schnellbrief des RFSS, 26.10.1938, zit. nach Maurer, Abschiebung und Attentat, S.61.

${ }^{84}$ Maurer, Abschiebung und Attentat, S.62f. Auch die Familie Grynszpan war vorab informiert, aber sie „wollten [...] das nicht glauben“, Postkarte von Berta Grynszpan an Herschel Grynszpan, 31.10.1938, in: Döscher, „Reichskristallnacht“, S. 60.

${ }^{85}$ Vgl. Barkai, „Schicksalsjahr 1938“, S. 110; Longerich, Politik, S. 197; Kershaw, Hitler, Bd.2, S. 194.

${ }^{86}$ Vgl. Döscher, „Reichskristallnacht“, S.63-65; Graml, Reichskristallnacht, S.9-12; Heiber, Grünspan, S. 141. 
tion seiner Familie, die Not litt und Herschel um Geld bat. ${ }^{87}$ Doch das fehlte ihm selbst, da er ohne Aufenthaltsgenehmigung keine Arbeit fand. Herschel Grynszpan hatte am eigenen Leib und bei seinen Angehörigen die Schikanen nationalsozialistischer Behörden erfahren und es war ihm nicht möglich, seine eigene Situation oder die seiner Familie zu verbessern. Es herrscht in der Forschung daher weitgehend Einigkeit, daß Herschel Grynszpan sich in einem Akt der Verzweiflung am NS-Regime rächen wollte und zu diesem Zweck auf den deutschen Diplomaten, Legationssekretär Ernst vom Rath, in Paris schoß. ${ }^{88}$ Grynszpan betrat am 7. November 1938 gegen 9.30 Uhr das Gebäude der deutschen Botschaft in Paris, fragte nach einem "Sekretär“ - einigen Darstellungen zufolge nach dem „Botschafter“ - und wurde daraufhin zum Legationssekretär Ernst vom Rath geführt. ${ }^{89}$ Auf diesen gab er mehrere Schüsse aus seinem Revolver ab, den er sich am Morgen gekauft hatte. Vom Rath wurde sofort in ein Krankenhaus eingeliefert und operiert, hatte aber so schwere Verletzungen davongetragen, daß mit seinem Tode zu rechnen war. ${ }^{90}$

Goebbels, der am 7. November nach München fuhr (TG, 8.11.1938), wo am 8. und 9. November des 15. Jahrestages von Hitlers Putschversuch gedacht werden sollte, erwähnte das Attentat Grynszpans nicht schon in seinem Eintrag über den 7. November (TG, 8.11.1938), sondern erst in der Notiz über den 8. November (TG, 9.11.1938). Goebbels hatte von dieser Tat entweder am 7. November 1938 noch keine Kenntnis oder, was wahrscheinlicher ist, interessierte sich angesichts seiner eigenen Sorgen nicht für die Körperverletzung eines unbedeutenden Beamten. Da Goebbels am 7. November an einem Empfang von Rudolf Heß teilnahm, wo er sich unter „all den alten Kameraden“ befand, denen das Attentat vermutlich Gesprächsstoff geboten hatte, ist eher anzunehmen, daß Goebbels dieser Tat keine große Bedeutung beimaß und sie deshalb nicht notierte (TG, 8.11. 1938). In seinem Eintrag vom Morgen des 9. November (TG, 9.11.1938) notierte Goebbels erstmals die Tat Grynszpans und nannte auch ein Motiv für Grynszpans Schüsse: „Aus Rache für die Juden“ (TG, 9.11.1938). Aus dem Tagebuch geht nicht hervor, auf welche Quelle sich Goebbels' Angabe über den Beweggrund Grynszpans stützte. In einem Bericht des Botschafters Graf Welczeck heißt es, Rath habe unmittelbar nach dem Anschlag erklärt, der Täter habe gesagt, er wolle „seine Glaubensgenossen rächen“.91 Später, als Grynszpan in NS-Schauprozessen

${ }^{87}$ Vgl. Döscher, „Reichskristallnacht“, S.68 (Abdruck des Textes, S.60); Graml, Reichskristallnacht, S.11; Heiber, Grünspan, S. 139.

${ }^{88}$ Vgl. Graml, Reichskristallnacht, S.12; Kropat, „Reichskristallnacht“, S.50; Maurer, Abschiebung und Attentat, S.70; Kershaw, Hitler, Bd.2, S. 194; Friedländer, Das Dritte Reich und die Juden, Bd.I, S.290; Longerich, Politik, S.198; Barkai, „Schicksalsjahr 1938“, S. 112; Heusler/Weger, „Kristallnacht“, S. 40.

${ }^{89}$ Vgl. Döscher, „Reichskristallnacht“, S.70, 77-79, 167f.; Graml, Reichskristallnacht, S.9; Kropat, „Reichskristallnacht“, S.50; Kershaw, Hitler, Bd.2, S.194; Heiber, Grünspan, S. $135,151$.

90 Vgl. Döscher, „Reichskristallnacht“, S.71; Kropat, „Reichskristallnacht“, S. 50.

${ }^{91}$ Der ausführliche Bericht Welczecks vom 8.11.1938 ging zwar erst am 10.11.1938 im A.A. ein, aber ihm war, wie es in dem Schreiben heißt, ein Telegramm vorausgegangen. Bericht Welczecks an das A.A., 8.11.1938, als Faksimile abgedr. in: Döscher, „Reichskristallnacht", S.77-79. Zum Motiv siehe auch: Friedländer, Das Dritte Reich und die Juden, Bd.I, S.290; Döscher, „Reichskristallnacht“, S.69; Heiber, Grünspan, S. 135. 
- zuerst in Paris, nach dessen Einnahme in Berlin - stellvertretend für das Weltjudentum angeklagt werden sollte, hatte er erklärt, er habe mit vom Rath ein homosexuelles Verhältnis gehabt. ${ }^{92}$ Doch weder die eigentlichen Motive interessierten die Nationalsozialisten noch die Person des Täters, sie betrachteten ihn „nur als Typ eines vom Weltjudentum gedungenen Werkzeuges“ ${ }^{93}$ Herschel Grynszpan wurde wahrscheinlich im Sommer 1942, nachdem der Schauprozess in Berlin abgesagt worden und er selbst somit für die Nationalsozialisten nutzlos geworden war und die „Endlösung der Judenfrage“ realisiert wurde, ohne Prozeß im KZ Sachsenhausen gehängt. ${ }^{94}$

\section{Der Novemberpogrom}

Kurz nachdem Hitler von den Schüssen am 7. November in der deutschen Botschaft in Paris Kenntnis erlangt hatte, beauftragte er zwei deutsche Ärzte, seinen Leibarzt Dr. Karl Brandt und Dr. Georg Magnus, dem schwerverletzten Legationssekretär vom Rath medizinische Hilfe zu leisten und ihm selbst über das Befinden des Opfers zu berichten; keine 24 Stunden nach dem Attentat trafen die Mediziner in Paris ein. ${ }^{95}$ Im Wissen, daß Raths Tod bevorstand, beförderte Hitler ihn zum „Gesandtschaftsrat erster Klasse“, obwohl Rath keine drei Wochen zuvor erst zum Legationssekretär ernannt worden war. ${ }^{96}$

Unmittelbar nach Bekanntwerden des Vorfalls in Paris setzte auch eine Flut von Presseanweisungen ein, ${ }^{97}$ die sich in aggressiven Zeitungsartikeln niederschlug ${ }^{98}$ und zu ersten antisemitischen Übergriffen führte. In Kassel und anderen Städten und Dörfern des Gaues Kurhessen wurden noch am Abend und in der Nacht des 7. Novembers von Parteigenossen und SA-Mitgliedern Synagogen verwüstet und jüdische Geschäfte zerstört. ${ }^{99}$ Am nächsten Tag wurde über die nächtlichen Aus-

92 Siehe hierzu: Steinweis, The Trials, S.471-488; Döscher, „Reichskristallnacht“, S.67, 159171; Heiber, Grünspan, S.134-172. In Goebbels' Augen handelte es sich bei dieser Behauptung Grynszpans um „eine unverschämte Lüge“ (TG,24.1.1942), aber gewisse Zweifel hatte er dennoch (TG, 14.5.1942).

${ }^{93}$ Schreiben Wolfgang Diewerges an Goebbels, 29. 10. 1941, BArch, R 55/20985, Bl.2-6.

94 Döscher, „Reichskristallnacht“, S. 172f.; Longerich, Politik, S. 199.

95 Vgl. Döscher, „Reichskristallnacht“, S.71; Steinweis, Kristallnacht, S.28; IfZ, Archiv, DNB-Berichte, Meldung Nr.30, 8.11.1938, Bl.21.

${ }^{96}$ NS-PrA, Bd. 6, Nr. 3185, 9.11.1938, S. 1054; Döscher, „Reichskristallnacht“, S. 87. Die vorausgegangene Beförderung war am 18.10.1938 erfolgt; Schreiben Friedrich Grimms an Diewerge nach Einsicht in Raths Personalakte, 14.2.1939, BArch, R 55/20990, Bl.14-16; Döscher, „Reichskristallnacht“, S. 68, 87.

${ }^{97}$ Im DNB-Rundruf vom 7.11.1938, 20.37 Uhr (NS-PrA, Bd. 6, Nr.3176, S. 1050), hieß es: „Alle deutschen Nachrichten müssen in größter Form über das Attentat auf den Legationssekretär an der deutschen Botschaft in Paris berichten. Die Nachricht muß die erste Seite voll beherrschen.“ Der Diplomat „schwebt in größter Lebensgefahr. In eigenen Kommentaren ist darauf hinzuweisen, daß das Attentat des Juden die schwersten Folgen für die Juden in Deutschland haben muß, und zwar auch für die ausländischen Juden in Deutschland." Vgl. auch Nr.3167, 3177-3181, 3184-3186, 3194, 3202 (S. 1047-1058).

$98 \mathrm{Vgl}$. Steinweis, Kristallnacht, S.27.

${ }^{99}$ Vgl. ebenda, S. 24-26; Kropat, „Reichskristallnacht“, S. 56-59 und S. 204-211 (Dok. 5-10); Longerich, Politik, S. 198. 
schreitungen in der hessischen Regional- und Lokalpresse groß und wohlwollend berichtet, und auch die übrigen Zeitungen im Reich schlugen einen aggressiven antisemitischen Ton an. ${ }^{100}$ Goebbels, der in der Regel die morgendliche Presse nicht in sein Tagebuch miteinbezog, notierte am Vormittag des 8. November kein Wort zu Demonstrationen oder Gewalttätigkeiten gegen Juden und auch nicht zum Attentat von Paris (TG, 8.11.1938).

Am 8. November und in der Nacht zum 9. November dehnte sich die Welle der Gewalt gegen Juden in Hessen räumlich und qualitativ aus. In mehr als zwei Dutzend Städten und Gemeinden Kurhessens kam es zu Ausschreitungen, häufig zu Mißhandlungen, gelegentlich zu Verhaftungen. In dieser Nacht wurden auch bereits Synagogen in Brand gesteckt. ${ }^{101}$ Hierüber war Goebbels informiert, wie ein Eintrag in sein Tagebuch belegt: „In Paris hat ein polnischer Jude Grynszpan auf den deutschen Diplomaten vom Rath in der Botschaft geschossen und ihn schwer verletzt. Aus Rache für die Juden. Nun aber schreit die deutsche Presse auf. Jetzt wollen wir Fraktur reden. In Hessen große antisemitische Kundgebungen. Die Synagogen werden niedergebrannt. Wenn man jetzt den Volkszorn einmal loslassen könnte!“ (TG, 9.11.1938) Goebbels wünschte also, den „Volkszorn“ in Form gelenkter, gewalttätiger Empörung von NS-Anhängern loslassen zu können, was darauf hindeutet, daß er selbst dies bis dahin nicht getan hatte und es noch keine zentral gesteuerte antisemitische Aktion gab. Es ist aus einer Reihe von Gründen auszuschließen, daß die Initiative zu den antisemitischen Ausschreitungen in Kurhessen von Goebbels ausging, wie Wolf-Arno Kropat annahm. ${ }^{102}$ Kropat begründet seine These damit, daß der Initiator der Pogrome im Gau Kurhessen, Gaupropagandaleiter Heinrich Gernand, später geäußert habe, er hätte „im Sinne des Reichspropagandaministeriums " gehandelt. ${ }^{103}$ Kropat bezieht sich hierbei auf eine kriminalpolizeiliche Vernehmung des Fuldaer NSDAP-Kreisleiters und Bürgermeisters von 1947, so daß sowohl die exkulpatorische Intention ${ }^{104}$ als auch eine möglicherweise ungenaue Erinnerung berücksichtigt werden müssen. Gegen Kropats These lassen sich noch weitere Argumente anführen: Erstens lehnte die Gauleitung in Kurhessen die Gewaltaktionen ab und erließ die Anweisung, die

100 Vgl. Kropat, „Reichskristallnacht“, S.60, 204f. (Dok. 5).

101 Vgl. Steinweis, Kristallnacht, S.29-35; Kropat, „Reichskristallnacht“, S.60-66, 208 (Dok 8).

102 Kropat, „Reichskristallnacht“, S.78.

103 Ebenda, S.76f., 208-211 (Dok.9). Jahre zuvor hatte Kropat, Kristallnacht in Hessen, S. 20-26, in Unkenntnis der von ihm später angegebenen Quelle eingeräumt, daß einige gewichtige Argumente gegen eine zentrale Steuerung der Pogrome in Hessen zwischen dem 7. und 9.11.1938 sprächen.

104 Karl Ehser, NSDAP-Kreisleiter und Bürgermeister von Fulda, mußte sich 1947 vor der Polizei wegen seiner Anweisung zur Inbrandsetzung der Synagoge in Fulda rechtfertigen. Er berief sich auf die „Anordnung“ des Gaupropagandaleiters Gernand, der Ehser zufolge angeblich übermittelt habe, was „vom Ministerium doch gewünscht“ worden sei. Ehser argumentierte, wenn er gegenüber der „Regierung“ eine „Befehlsverweigerung" begangen hätte, hätte dies für ihn „böse Folgen“" gehabt. Vgl. polizeiliche Vernehmung Karl Ehsers durch die Kriminalpolizei Fulda, 27.5.1947, in: Kropat, „Reichskristallnacht", Dok.9, S.208-211. 
„Demonstrationen [...] sofort einzustellen“. ${ }^{105}$ Wenn das Propagandaministerium - oder Goebbels - Kurhessen als Ort der Initialzündung der Pogrome gegen Juden auserkoren hätte, so wäre die Gauleitung sicherlich zumindest unterrichtet worden und hätte nicht gegenteilige Anordnungen erlassen. Zweitens stellt sich die Frage, wieso gerade Kurhessen diese Funktion übernehmen hätte sollen, zumal Goebbels mit dem kurhessischen Propagandaleiter Gernand in keinem besonderen Verhältnis stand und ihn bis Kriegsbeginn kein einziges Mal in seinem Tagebuch erwähnte. Wahrscheinlicher wäre doch gewesen, daß Goebbels, wenn er die Ausschreitungen angestiftet hätte, einen Gauleiter seines Vertrauens mit dieser heiklen Mission betraut hätte. Drittens wäre die Frage zu beantworten, weshalb Goebbels, wenn die Pogrome auf seine Idee zurückgingen, nicht sogleich in Berlin derartige Ausschreitungen angeordnet hatte, schließlich war dieses Mittel von ihm bereits im Frühsommer 1938 angewandt worden. Viertens erwähnte Goebbels in seinem Tagebuch nicht, daß er die Anweisung zu den ersten Pogromen gegeben habe, ${ }^{106}$ was er, wäre es der Fall gewesen, mit Sicherheit notiert hätte, so wie er mehrere vergleichbare eigene antijüdische Aktionen festhielt. Im Gegenteil, Goebbels bedauerte, daß nicht im großen Stil Pogrome veranstaltet würden und hoffte, daß der "Volkszorn“ gegen Juden „jetzt" losgelassen werden könnte (TG, 9.11.1938). Goebbels hieß die Ausschreitungen in Kurhessen gut, aber er hatte sie nicht angeordnet. Die Pogrome in Kurhessen gingen offensichtlich von dem dortigen Gaupropagandaleiter aus, der aus eigener Initiative handelte.

Ein aktives Eingreifen der obersten NS-Führung war für antijüdische Ausschreitungen im November 1938 auch nicht mehr erforderlich. Bereits nach der Ermordung Wilhelm Gustloffs, NSDAP-Landesleiter in der Schweiz, am 4. Februar 1936 durch den jüdischen Studenten David Frankfurter wollte Goebbels „größere Aktionen“ gegen die Juden „machen“ (TG, 6.2.1936). In sein Tagebuch schrieb er damals: „Das wird den Juden teuer zu stehen kommen“ (TG, 6.2.1936). Dieselbe Formulierung sollte er zweimal anläßlich der Novemberpogrome benutzen. ${ }^{107}$ Der Gedanke der Rache war schon damals vorhanden. Doch wegen der bevorstehenden olympischen Winterspiele in Garmisch-Partenkirchen, die das NS-Regime zur positiven Selbstdarstellung gegenüber dem skeptischen Ausland nutzen wollte, überlegten Hitler und Goebbels lange mögliche Gegenmaßnahmen (TG, 6.2.1936). Letztlich entschieden sie damals wegen der Außenwirkung gegen antijüdische Aktivitäten. Um auch besonders eifrige Nationalsozialisten von Pogromen in eigener Initiative abzuhalten, gab der Stellvertreter des Führers die Anordnung aus, daß „Einzelaktionen gegen Juden aus Anlaß der Ermordung des Leiters der Landesgruppe Schweiz der NSDAP [...] unbedingt zu unterbleiben

105 Anordnung des Regierungspräsidenten in Kassel an die Ortspolizeibehörden und Polizeidienststellen im Regierungsbezirk Kassel, 8.11.1938, 16.35 Uhr, in: Kropat, „Reichskristallnacht", Dok.7, S.207; siehe auch ebenda, S.76-78.

106 So auch Barth, Goebbels und die Juden, S. 133 und Anm. 288.

107 Nach dem Tode vom Raths und der Pogromnacht notierte Goebbels: „Dieser Tote kommt dem Judentum teuer zu stehen“, TG, 10.11.1938; nach der Besprechung bei Göring am 12.11.1938: „Der Tote kommt den Juden teuer zu stehen“, TG, 13.11.1938. 
haben"108. Ausdrücklich wies Rudolf Heß in diesem Rundschreiben darauf hin, daß die Entscheidung zu derartigen Maßnahmen bei Hitler liege: „Es bleibt nach wie vor dem Führer allein überlassen, welche Politik von Fall zu Fall einzuschlagen ist. Kein Parteigenosse darf Politik auf eigene Faust treiben" 109 Schon im Februar 1936 sah die NSDAP also die Notwendigkeit, ihren Mitgliedern Übergriffe gegen Juden zu untersagen. Im November 1938 waren Aktionen gegen Juden, vor allem in Österreich und dem Sudetenland, an der Tagesordnung und die antijüdische Stimmung weiter verbreitet, so daß insbesondere aufgrund der Pressekampagne, die auf das Grynszpan-Attentat folgte, ,judenfeindliche Aktionen nicht nur möglich oder wahrscheinlich, sondern gewiß" waren. ${ }^{110}$ Bereits unmittelbar nach dem Münchener Abkommen hatten vereinzelte lokale Pogrome, insbesondere in den Gauen Franken und Württemberg, stattgefunden, in denen sich die krisenbedingte Angst und Aggression in Gewalt gegen jüdische Nachbarn entlud. ${ }^{111}$ Für derartige Maßnahmen im gesamten Reichsgebiet fehlte den Nationalsozialisten aber wohl noch ein Anlaß. So ließe sich Goebbels’ Bedauern darüber, nun „den Volkszorn" noch nicht in Bewegung setzen zu können (TG,9.11.1938), als ungeduldiges Warten deuten, wann der todgeweihte vom Rath seinen Verletzungen erliegen würde. ${ }^{112}$ Noch ergingen keine Befehle zu einem Pogrom, der sich auf das gesamte Staatsgebiet erstrecken sollte. Allerdings läßt sich aus dem GoebbelsTagebuch nicht erkennen, daß Goebbels mit Hitler vor dem 9. November über mögliche reichsweite Pogrome gesprochen hätte. Gelegenheit zu einer solchen Unterhaltung wäre in der Nacht vom 8. auf den 9. November gewesen, als Hitler bis 3.00 Uhr morgens in seinem Münchener Stammcafé Heck mit seinen engsten Vertrauten „alle möglichen Fragen“ durchsprach, wie Goebbels überliefert (TG, 9.11.1938).

Am Vormittag des 9. November 1938 fand in München „der traditionelle Marsch vom Bürgerbräu zur Feldherrnhalle und dann zum Königlichen Platz“ statt (TG, 10.11.1938), der alljährlich das Andenken an den gescheiterten Putschversuch Hitlers von 1923 bewahren sollte. ${ }^{113}$ Zur selben Zeit wurde dem Auswärtigen Amt mitgeteilt, daß „noch heute“ mit dem Tode vom Raths „gerechnet werden müsse“. 114 Am Nachmittag zog sich Goebbels in sein Hotel zurück, um die

108 Anordnung Nr.17/36 des Stellvertreters des Führers, Rudolf Heß, 5.2.1936, streng vertraulich, an alle Reichsstatthalter, Landesregierungen, Preußischen Oberpräsidenten und Polizeibehörden, Gauleitungen. Die Gauleitungen wurden aufgefordert, „sämtlichen untergeordneten Parteidienststellen sofort telefonisch oder telegraphisch den Inhalt dieses Runderlasses zur Kenntnis zu geben“. Österreichisches Staatsarchiv, Archiv der Republik, 04: Inneres/Justiz, Reichskommissar für die Wiedervereinigung Österreichs mit dem Deutschen Reich, Bürckel/Materie, Mappe 4210, Karton 192.

109 Ebenda.

110 Vgl. Graml, Reichskristallnacht, S. 13.

111 Vgl. Kulka/Jäckel, Die Juden, Dok.350f., 353.

112 Ähnlich Friedländer, Das Dritte Reich und die Juden, Bd.I, S.293, der diese Tagebuchpassage noch nicht kannte, aber meinte, Hitler und Goebbels haben „wahrscheinlich beschlossen, den Tod des schwerverletzten Rath abzuwarten“. So auch Adam, Wie spon$\tan$, S. $91 \mathrm{f}$.

113 Zur Route siehe Heusler/Weger, „Kristallnacht“, S.42f.

114 Zit. nach Döscher, „Reichskristallnacht“, S. 87. 
Presse zu studieren, zu arbeiten und an seiner kürzlich begonnenen Hitler-Biographie $^{115} \mathrm{zu}$ schreiben (TG, 10.11.1938). Vermutlich im Hotel erfuhr Goebbels, daß es unmittelbar zuvor in „Kassel und Dessau große Demonstrationen gegen die Juden“ gegeben hatte, daß „Synagogen in Brand gesteckt und Geschäfte demoliert" worden waren (TG, 10.11.1938). ${ }^{116}$ Auch für Dessau dürfte gelten, daß die Aktion nicht vom Propagandaministerium ausging, sondern von regionalen oder lokalen Stellen, da Rath zu diesem Zeitpunkt noch immer lebte. ${ }^{117}$ Der eben zum Gesandtschaftsrat beförderte Ernst vom Rath verstarb am Nachmittag des 9. November um 16.30 Uhr Ortszeit in Paris. Karl Brandt sandte diese Nachricht 15 Minuten später telegraphisch an Hitler. Um 18.20 Uhr traf das Telegramm in Berlin ein. ${ }^{118}$ Döscher folgert daraus, daß Hitler „bis spätestens $20 \mathrm{Uhr}$ vom Tode Raths Kenntnis hatte “ ${ }^{119}$ Bislang war zumeist aufgrund einer Aussage F. K. von Ebersteins davon ausgegangen worden, Hitler habe erst „etwa um 21 Uhr“ durch einen „Boten“ während des „Kameradschaftsabends der Alten Kämpfer“ davon erfahren. ${ }^{120}$ Peter Longerich überprüfte Zeugenaussagen und konnte dadurch bestätigen, daß der Tod Raths schon vor Beginn der Parteiversammlung im Alten Rathaus bekannt war. ${ }^{121}$ In dieser nicht unwesentlichen Frage nach dem Zeitpunkt, zu dem die Meldung aus Paris eintraf, liefern die Goebbels-Tagebücher Gewißheit, denn Goebbels notierte: „Nachmittags wird der Tod des deutschen Diplomaten vom Rath gemeldet" (TG, 10.11.1938). Es wäre auch merkwürdig, wenn Hitler diese wichtige Nachricht nicht sofort telefonisch gemeldet worden wäre, da er doch zwei Ärzte „zur Berichterstattung nach Paris“ entsandt hatte, die ihn laufend über den Zustand Raths zu informieren hatten. ${ }^{122}$ Goebbels und Hitler wußten also bereits am Nachmittag, daß Rath verstorben war. ${ }^{123}$

Aus den Tagebüchern von Goebbels läßt sich nicht erkennen, daß Hitler und Goebbels vor dem traditionellen „Kameradschaftsabend“ im Alten Rathaus in München miteinander gesprochen hätten, weder in Hitlers Privatwohnung noch

115 Die z.B. von Meissner, Magda Goebbels, S.247, und Longerich, Goebbels, S.399, vertretene These, Goebbels habe diese Hitler-Biographie nach der Baarova-Affäre nur oder in erster Linie aus Gründen der Rehabilitierung bei Hitler geschrieben, läßt sich durch die Tagebücher nicht belegen.

116 Der Pogrom in Dessau begann am 9.11.1938 gegen 15.00 Uhr (Kropat, „Reichskristallnacht“, S.79), in Kassel selbst blieb es am Nachmittag des 9.11. ruhig, aber in einigen anderen Städten Nordhessens fanden Ausschreitungen statt (Kropat, „Reichskristallnacht", S. 68-72; Döscher, „Reichskristallnacht“, S. 85f.).

117 Steinweis, Kristallnacht, S.41, verweist auf das lokale NS-Blatt, das die Namen der 204 jüdischen Familien in Dessau veröffentlichte.

118 Telegramm Brandts an Hitler, als Faksimile abgedr. in: Döscher, „Reichskristallnacht“, S. 81, 87.

119 Döscher, „Reichskristallnacht“, S. 88.

120 Aussage des Höheren SS- und Polizeiführers und Münchener Polizeipräsidenten, Friedrich Karl v. Eberstein, am 3.8.1946 vor dem IMG, in: IMG 20, S.320. Diese wird in allen einschlägigen Publikationen zitiert oder erwähnt.

121 Longerich, Politik, S. 199.

122 IfZ, Archiv, DNB-Berichte, Meldung Nr.30, 8.11.1938, Bl.21. Ähnlich argumentiert Kershaw, Hitler, Bd.2, S. 195.

123 Below, Hitlers Adjutant, S. 136. 
auf einer gemeinsamen Autofahrt zum Versammlungsort. ${ }^{124}$ Vielmehr dürfte Goebbels Hitler erst gegen 18.00 Uhr im Rathaussaal getroffen haben, was erklären würde, warum der „Führer“ „während dieses Essens eine außerordentlich eindringliche Unterredung mit Goebbels“ hatte. ${ }^{125}$ Goebbels trug seinem Tagebuch zufolge „dem Führer die Angelegenheit vor“ (TG, 10.11.1938), informierte ihn also über den Tod des Diplomaten. Wenn Hitler, wie überliefert wurde, von der ihm im Rathaussaal überbrachten Todesnachricht Raths, stärkstens beeindruckt “126 gewesen sei, dürfte es sich hierbei um eine „theatralische Inszenierung"127 handeln, so wie Hitler auch in anderen Situationen eine gewisse schauspielerische Neigung erkennen ließ. Goebbels informierte Hitler auch über die Ausdehnung der antijüdischen Ausschreitungen am Nachmittag des 9. November in den Gauen Kurhessen und Magdeburg-Anhalt, wo „große Demonstrationen gegen die Juden“ veranstaltet worden waren und, wie er weiter vermerkte, „Synagogen in Brand gesteckt und Geschäfte demoliert" worden waren (TG, 10.11.1938). ${ }^{128}$ Die darauf folgende Tagebuchpassage, die seit 1992 bekannt ist, ${ }^{129}$ klärt eindeutig die Verantwortlichkeit für die reichsweiten Pogrome. Goebbels schrieb über sein Gespräch mit Hitler in der Versammlung: „Er bestimmt: Demonstrationen weiterlaufen lassen. Polizei zurückziehen. Die Juden sollen einmal den Volkszorn zu verspüren bekommen“ (TG, 10.11.1938). Goebbels fand das „richtig“ und gab „gleich entsprechende Anweisungen an Polizei und Partei“ (TG, 10.11.1938), die sich zwar in den Quellen nicht nachweisen lassen, aber erklären, weshalb es bereits ab 19.00 Uhr in einigen Städten des Reiches zu antijüdischen Ausschreitungen kam. ${ }^{130}$

Die zitierte Passage „Er bestimmt: Demonstrationen weiterlaufen lassen“ (TG, 10.11.1938) aus den Goebbels-Tagebüchern ist besonders aufschlußreich. Zum einen belegt sie, daß Goebbels mit Hitler die nun folgenden Maßnahmen besprach, daß also Hitler nicht vor vollendete Tatsachen gestellt wurde, wie mancher Zeitzeuge zur Ehrenrettung des „Führers“ behauptet hatte. ${ }^{131}$ Zum anderen beweist sie, daß Hitler die Verantwortung für den Pogrom trägt, da Hitler „bestimmt“ hatte, die „Demonstrationen weiterlaufen“ zu lassen. Goebbels wußte,

124 Dietrich, Zwölf Jahre, S.55f.; Kershaw, Hitler, Bd.2, S. 195.

125 Aussage Ebersteins vom 3.8.1946, in: IMG 20, S.320. Die Versammlung begann um 18.00 Uhr; vgl. Einladungskarte zum „Gesellige[n] Beisammensein der Führerschaft der NSDAP“ im Festsaal des Alten Rathauses, 9. November 1938, 18.00 Uhr; StadtAM, Bürgermeister und Rat, Nr.458/3 (als Faksimile publiziert bei Heusler/Weger, „Kristallnacht", S.46).

126 Aussage Ebersteins vom 3.8.1946, in: IMG 20, S. 320.

127 Longerich, Politik, S. 199.

128 Vgl. Kropat, „Reichskristallnacht“, S.68-72, 79; Döscher, „Reichskristallnacht“, S. 85f.

129 Wissenschaftlich verwertet wurde die Passage erstmals u. a. von Friedländer, Das Dritte Reich und die Juden, Bd.I, S.294; Longerich, Politik, S.199; Kershaw, Hitler, Bd.2, S. 196.

130 Beispielsweise in Chemnitz und Lüneburg; vgl. Kropat, „Reichskristallnacht“, S. 80.

131 In diesem Sinne äußerte sich SS-Hauptsturmführer Luitpold Schallermeier am 5.7. 1946, der persönliche Referent des Chefs des Persönlichen Stabes des RFSS Karl Wolff; Affidavit SS-5, in: IMG 42, S.512. Auch Below, Hitlers Adjutant, S. 136f., berichtet von einer angeblichen Überraschung Hitlers. 
was er unter „weiterlaufen lassen“ zu verstehen hatte. ${ }^{132}$ Dieser Befehl Hitlers implizierte nicht nur das Verbot, bereits laufende Aktionen einzudämmen. Goebbels sollte vielmehr dafür sorgen, daß die Gewalttätigkeiten anhielten, daß sie weiter liefen, daß sie ausgedehnt wurden. Im selben Tagebucheintrag berief sich Goebbels noch zweimal auf diesen Führerbefehl, um die Verantwortung Hitlers für die ungewöhnliche, von Goebbels gleichwohl gebilligte Maßnahme deutlich festzuhalten: „Diesen feigen Mord dürfen wird nicht unbeantwortet lassen. Mal den Dingen ihren Lauf lassen“ (TG, 10.11.1938). „Jetzt rast der Volkszorn. Man kann für die Nacht nichts mehr dagegen machen. Und ich will auch nichts machen. Laufen lassen" (TG, 10.11.1938).

Unmittelbar danach sprach Goebbels im Sinne von Hitlers Anweisungen zu den „Alten Kämpfern“ und NSDAP-Funktionären im Rathaussaal und vermerkte darüber im Tagebuch: „Dann rede ich kurz dementsprechend vor der Parteiführerschaft. Stürmischer Beifall. Alles saust gleich an die Telephone. Nun wird das Volk handeln“ (TG, 10.11.1938). Der genaue Wortlaut der Rede ist unbekannt. Überliefert ist, daß Goebbels zunächst den Tod Raths und die antisemitischen Ausschreitungen in den Gauen Kurhessen und Magdeburg-Anhalt erwähnt und schließlich erklärt hat, Hitler habe „auf seinen Vortrag entschieden“, daß derartigen Demonstrationen „nicht entgegenzutreten“ sei. ${ }^{133}$ Die Parteiführerschaft faßte die Ansprache so auf, „daß die Partei nach außen nicht als Urheber der Demonstrationen in Erscheinung treten, sie in Wirklichkeit aber organisieren und durchführen sollte", wie das Oberste NSDAP-Parteigericht wenige Monate später feststellte. ${ }^{134}$ Die Weiterleitung der Befehle an die Kreis- und Ortsgruppenleiter sowie an die Untergliederungen anderer NS-Verbände war zum Teil, wie das Parteigericht befand, „so verstanden“ worden, „daß nun für das Blut des Pg. vom Rath Judenblut fließen müsse, daß es jedenfalls nach dem Willen der Führung auf das Leben eines Juden nicht ankomme“ "135. Goebbels selbst charakterisierte seine Rede im Tagebuch als Initialzündung zum Pogrom, da nun die Parteiführerschaft "an die Telephone" gelaufen sei; und Goebbels erwartete, daß nun sie „handeln“ werde, d.h. das Volk zum Handeln bringen werde (TG, 10.11.1938). Zwar war es in den meisten Fällen nicht in erster Linie das einfache Volk, das die Gewalttätigkeiten verübte oder wünschte, ${ }^{136}$ sondern das Millionenheer der Parteigenossen, aber erstens repräsentierten die Parteimitglieder in Goebbels' Augen das Volk, zweitens hofften die Nationalsozialisten, daß sich das Volk im großen Stil an den

132 Sämtliche kursiven Hervorhebungen in diesem Absatz durch d.V.

133 Bericht des Obersten Parteigerichts an Göring vom 13.2.1939, in: IMG 32, Dok. 3063 PS, S. 20-29, hier S. 21.

134 Ebenda, S. 21.

135 Ebenda, S.26f.

${ }^{136}$ Im November-Bericht der Exil-SPD hieß es dazu: „Alle Berichte stimmen dahin überein, daß die Ausschreitungen von der großen Mehrheit des deutschen Volkes scharf verurteilt werden." Deutschland-Berichte (Sopade), Bd.5, S.1204f. So auch Longerich, Politik, S. 204; Kropat, „Reichskristallnacht“', S. 158f., 169; Bericht über Stimmung nach Pogrom in München, in: Barkow/Gross/Lenarz, Novemberpogrom 1938, S.480f.; Wildt, Volksgemeinschaft, 2007, S.342-347. Zur Beteiligung der „einfachen“ Volksgenossen siehe Steinweis, Kristallnacht, v.a. S.119-147. 
Übergriffen gegen die Juden beteiligen würde, und drittens entsprach es der Taktik und Sprachregelung der Nationalsozialisten, offiziell den Pogrom als Affekthandlung des Volkes ${ }^{137}$ darzustellen. Doch fast jeder wußte, daß es sich nicht um „spontanen Volkszorn“ handelte - weder in Berlin noch anderswo. Dies geht auch aus dem Bericht des Obersten Parteigerichtes der NSDAP vom Februar 1939 hervor. „Auch die Öffentlichkeit“ wisse „bis auf den letzten Mann, daß politische Aktionen wie die des 9. November von der Partei organisiert und durchgeführt sind, ob dies zugegeben wird oder nicht“. Weiter wurde darin ausgeführt: „Wenn in einer Nacht sämtliche Synagogen abbrennen, so muß das irgendwie organisiert sein und kann nur organisiert sein von der Partei“. 138

Nachdem Goebbels seine Rede vor den versammelten Parteiführern im Festsaal des Alten Rathauses beendet hatte, setzte eine Flut von Anweisungen verschiedener parteilicher und staatlicher Institutionen auf allen Ebenen ein. Goebbels hatte in seiner Rede bewußt keine eindeutigen Befehle ausgesprochen, so daß die Reichsregierung nicht diskreditiert wurde und es nun im Ermessen eines jeden Parteifunktionärs lag, wie exzessiv er die Verfolgung der Juden betreiben ließ. In einigen Fällen scheint Goebbels aber doch zu aggressiverem Verhalten angespornt zu haben, wie aus seinem Tagebuch hervorgeht: „Einige Laumänner machen schlapp. Aber ich reiße immer wieder alles hoch. Diesen feigen Mord dürfen wir nicht unbeantwortet lassen" (TG, 10.11.1938). Im ganzen Reich interpretierten die Parteiführer auf jeweils unterschiedliche Weise, was nun zu tun war. Diese „für die Nationalsozialisten typische Art der indirekten, intuitiv zu erfassenden Befehlsgebung hatte“ Peter Longerich zufolge „den Vorteil, daß die Befehlsgeber keine juristisch nachweisbare Verantwortung übernahmen, sie schloß andererseits das Risiko ein, daß einige der Untergebenen den Sinn der Anweisung nicht richtig verstanden und entweder nicht radikal genug vorgingen oder umgekehrt in ihrem Übereifer über das Ziel hinausschossen". ${ }^{39}$ So hatte sich dann auch das Oberste Parteigericht einige Monate nach dem Pogrom mit den Folgen, die die „nicht immer sehr glücklich formulierten Befehle“, wie es befand, verursacht hatten, zu befassen. Zur Ursache für die 91 angeführten Mordfälle an Jüdinnen und Juden erklärte das Gericht „,in all diesen Fällen ein Mißverständnis in irgend einem Glied der Befehlskette“. ${ }^{140}$ Einige dieser Morde kamen auch Goebbels sogleich zu Ohren. „Nur in Bremen ist es zu einigen unliebsamen Exzessen gekommen“ (TG, 11.11.1938). ${ }^{141}$ Daß Goebbels an der Tötung einiger Juden nicht im gering-

137 Vgl. z.B. eine Presseanweisung vom 10.11.1938: „Wenn Kommentare für nötig befunden würden, so sollen sie nur kurz sein und etwa sagen, daß eine begreifliche Empörung der Bevölkerung eine spontane Antwort auf die Ermordung des Gesandtschaftsrates gegeben habe." In: NS-PrA, Bd.6, Nr.3209, S. $1060 \mathrm{f}$.

138 Bericht des Obersten Parteigerichts an Göring vom 13.2.1939, in: IMG 32, Dok. 3063PS, S.27.

139 Longerich, Politik, S. 201.

140 Bericht des Obersten Parteigerichts an Göring vom 13.2.1939, in: IMG 32, Dok.3063PS, S.26.

141 Aus dem Raum Bremen sind für den 9. und 10.11.1938 5 Morde an Juden überliefert; Kropat, „Reichskristallnacht“, S.111. Siehe auch die Urteilsbegründung des parteiinternen Untersuchungsverfahrens wegen der Morde in Lesum, in: VEJ, Bd.2, Dok. 134. 
sten Anstoß nahm, belegt ein Tagebucheintrag über den Morgen danach: „Die Aktion selbst ist tadellos verlaufen. 17 Tote. ${ }^{142}$ Aber kein deutsches Eigentum beschädigt“ (TG, 11.11.1938). Lediglich Schäden an „arischem“ Besitz sollten, wie Goebbels deutlich macht, vermieden werden, nicht der Tod jüdischer Personen. Wieviele Menschen am 9. und 10. November 1938 tatsächlich ermordet wurden, ist nicht mehr restlos aufzuklären; insgesamt ist von etwa 1300 bis 1500 jüdischen Todesfällen während und infolge der Pogrome auszugehen sowie von 1406 zerstörten Synagogen und Betstuben und ca. 8000 verwüsteten Geschäften. ${ }^{143}$

Am 9. November, noch vor Mitternacht, wurden in München die Ohel-JakobSynagoge in der Herzog-Rudolf-Straße und die Synagoge in der Reichenbachstraße zerstört. ${ }^{144}$ Goebbels notierte hierzu: „Eine Synagoge wird in Klump geschlagen“ (TG, 10.11.1938). Mit dem Münchener Gauleiter Adolf Wagner begab sich Goebbels zur Gaugeschäftsstelle des „Traditionsgaues“, um dort per Fernschreiben Anweisungen an die Gaupropagandaämter zu übermitteln: „Ich gebe noch ein präzises Rundschreiben heraus, in dem dargelegt wird, was getan werden darf und was nicht“ ${ }^{145}$ Entgegen den bisherigen Forschungen, die Gauleiter Wagner in der Reichskristallnacht als federführend für die Pogrome in München dargestellt hatten, ${ }^{146}$ überliefert Goebbels, dieser habe „kalte Füße“ bekommen (TG, 10.11. 1938). Anschließend begab sich Goebbels zur Vereidigung der SS-Rekruten, die traditionell eine Ansprache Hitlers umfaßte und vor der Feldherrnhalle stattfand, seit 1936 um Mitternacht. Nach dem Ende der Prozedur, gegen 1.00 Uhr, wollte Goebbels sich im Hotel „Vier Jahreszeiten“ schlafen legen und sah auf dem Weg dorthin die dahinter befindliche Synagoge in Flammen stehen: „Ich will ins Hotel, da sehe ich den Himmel blutrot. Die Synagoge brennt. "147 Daraufhin kehrte

142 Die von Goebbels festgehaltene, relativ niedrige Opferzahl gibt seinen Kenntnisstand am Morgen des 10.11.1938 wieder. Heydrich gab in einem ersten Bericht vom 11.11.1938 an, es seien 36 Todesfälle und 36 Fälle von Schwerverletzten gemeldet worden. Schnellbrief des Chefs der Sicherheitspolizei an den Preußischen Ministerpräsidenten, in: IMG 32, Dok.3058-PS, S.2.

143 Diese Zahlen umfassen neben den Morden während der Pogrome auch die in den Selbstmord Getriebenen sowie die Todesfälle von damals in Konzentrationslager verschleppten Menschen. Sie basieren auf den langjährigen Forschungen des Synagogue Memorial, Jerusalem, unter der Leitung von Meier Schwarz; vgl. ders.: Die „Kristallnacht“-Lüge, URL: <http://www.schoah.org/schoah/kristallnacht.htm> [30.11. 2010]. Heydrich nannte bei der Konferenz bei Göring die Zahl von 7500 zerstörten jüdischen Geschäften. Stenographische Niederschrift der Besprechung über die Judenfrage bei Göring, 12.11.1938, in: IMG 28, Dok.1816-PS, S.517; VEJ, Bd.2, Dok.146, S.415. In der Forschungsliteratur wird meist die Zahl von 8000 zerstörten Geschäften genannt; vgl. z. B. Graml, Reichskristallnacht, S.32; Kershaw, Hitler, Bd.2, S. 199.

$144 \mathrm{Zu}$ den Zerstörungen der Synagogen siehe Heusler/Weger, „Kristallnacht“, S. 65-71, 7483.

145 Dieses Rundschreiben, abgesandt um 0.30 Uhr, eingegangen gegen $1.40 \mathrm{Uhr}$ am 10.11.1938, ist nicht überliefert, aber existierte nachweislich; vgl. Bericht des Obersten Parteigerichts an Göring vom 13.2.1939, in: IMG 32, Dok.3063-PS, S.21f.

146 Heusler/Weger, „Kristallnacht“, S. 49; Kropat, „Reichskristallnacht“, S. 81.

147 Hierbei handelte es sich um die Synagoge in der Herzog-Rudolf-Straße, denn die Hauptsynagoge war bereits im Juni 1938 abgerissen worden und in der Synagoge in der Reichenbachstraße war lediglich ein „Kleinfeuer“ ausgebrochen; Heusler/Weger, „Kristallnacht", S.35-37, 65-71, 74-83. Auch die Chronologie legt dies nahe, denn die Verei- 
Goebbels noch einmal zur Gauleitung von München und Oberbayern zurück, wo ihm zufolge „noch niemand etwas“ gewußt habe (TG, 10.11.1938). Die Unkenntnis vom Brand der Synagoge bei der Gauleitung läßt ebenfalls den Schluß zu, daß diese die Inbrandsetzung nicht befohlen hatte. Vielmehr überliefert Goebbels, daß Adolf Wagner bei der Nachricht der brennenden Synagoge und den Meldungen aus anderen Städten „noch immer etwas lau“ gewesen sei. Die Brandstiftung von Ohel Jakob geschah also nicht auf Befehl des oberbayerischen Gauleiters oder des dortigen Gaupropagandaleiters. Goebbels notierte dazu weiter: „Wir lassen nur soweit löschen, als das für die umliegenden Gebäude notwendig ist. Sonst abbrennen lassen" (TG, 10.11.1938). Diese Vorgehensweise entsprach genau den Anweisungen, die Heydrich von Himmler erhalten hatte und die er an die Staatspolizei und den SD weiterleitete. ${ }^{148}$ Bei der Gauleitung erfuhr Goebbels, daß auch in anderen Städten die Synagogen brannten: „Aus dem ganzen Reich laufen nun die Meldungen ein: 50, dann 75 Synagogen brennen“ (TG, 10.11.1938). Drei Tage später berichtete Heydrich Goebbels, daß „190 Synagogen verbrannt und zerstört seien" (TG, 13.11.1938). ${ }^{149}$ Diese neue Zahl kommentierte Goebbels mit den Worten: „Das hat gesessen“ (TG, 13.11.1938). Goebbels war daran interessiert, zu wissen, wieviele jüdische Gotteshäuser und Menschenleben bei dem Pogrom vernichtet wurden, und aktualisierte im Tagebuch mehrmals seinen Kenntnisstand. In der Münchener Gauleitung brachte Goebbels auch die beginnende Festnahme Tausender Juden in Erfahrung: „Der Führer hat angeordnet, daß 25-30 000 Juden sofort zu verhaften sind" (TG,10.11.1938). ${ }^{150}$ Auch in diesem Fall überliefert

digung der SS war erst gegen 1.00 Uhr zu Ende (Adam, Wie spontan, S.78), Goebbels war sicher nicht vorher gegangen. Um 1.02 Uhr rückte der erste Löschzug zur HerzogRudolf-Straße aus; vgl. Heusler/Weger, „Kristallnacht“, S. 68.

148 In einem Blitz-Fernschreiben Heydrichs an untergeordnete Behörden der Staatspolizei und des SD ordnete Heydrich u.a. folgendes an: „Es dürfen nur solche Maßnahmen getroffen werden, die keine Gefährdung deutschen Lebens oder Eigentums mit sich bringen (z. B. Synagogenbrände nur, wenn keine Brandgefahr für die Umgebung vorhanden ist)." Blitz-Fernschreiben des SS-Gruppenführers und Chefs der Sicherheitspolizei Heydrich an alle Staatspolizeileit- und Staatspolizeistellen und SD-Ober- und Unterabschnitte, 10.11.1938, 1.20 Uhr, in: IMG 31, Dok.3051-PS, S.515-518, hier S.516. Auch abgedr. in: Kropat, „Reichskristallnacht“, Dok. 14, S.214-216, und Döscher, „Reichskristallnacht“, S.95-97.

149 Ein schriftlicher Bericht Heydrichs an Göring beziffert die Zahl der Synagogen, die „in Brand gesteckt" wurden, auf 191, weitere 76 seien „vollständig demoliert" worden. Schnellbrief des Chefs der Sicherheitspolizei Heydrich an den Preußischen Ministerpräsidenten, 11.11.1938, in: IMG 32, Dok.3058-PS, S.2. Im Protokoll der Konferenz im Reichsluftfahrtministerium gab Heydrich an, es seien „im ganzen 101 Synagogen durch Brand zerstört, 76 Synagogen demoliert" worden. Stenographische Niederschrift der Besprechung über die Judenfrage bei Göring am 12.11.1938, in: IMG 28, Dok. 1816-PS, S.508; VEJ, Bd.2, Dok. 146, S. 415.

150 Die Anordnung, die „Festnahme von etwa 20-30000 Juden im Reiche“ vorzubereiten, sandte der Chef des Geheimen Staatspolizeiamts, Heinrich Müller, per Fernschreiben um kurz vor Mitternacht allen Staatspolizeileitstellen zu. Außerdem ordnete er darin an, die „Aktionen“ gegen Juden und Synagogen „nicht zu stören“ und Plünderungen zu verhindern. Geheimes Fernschreiben der Gestapo an alle Staatspolizeileit- und Staatspolizeistellen, 9.11.1938, 23.55 Uhr, in: IMG 25, Dok.374-PS, S.377f. Auch abgedr. in: Kropat, „Reichskristallnacht“, S.213f., und Döscher, „Reichskristallnacht“, S. 98. 
Goebbels also eindeutig eine Anweisung Hitlers, die mit vermutlich 30756 festgenommenen Juden mehr als erfüllt wurde. ${ }^{151}$ Goebbels scheint davon ausgegangen zu sein, daß diese Juden alle ermordet werden sollten. Als ihm gegen $2 \mathrm{Uhr}$ morgens ein erster Toter aus München gemeldet wurde - Chaim Both, ein Münchener Jude polnischer Nationalität -, soll er dem Überbringer der Nachricht geantwortet haben, er „solle sich wegen eines toten Juden nicht aufregen, in den nächsten Tagen würden Tausende von Juden daran glauben müssen“.152 Wenig später verfolgte Goebbels im Künstlerklub gespannt die weiteren Meldungen, vor allem aus Berlin: „In Berlin brennen 5, dann 15 Synagogen.“ Als Goebbels ins Hotel fuhr, klirrten Fensterscheiben. Euphorisch kommentierte er den Pogrom: „Bravo! Bravo! In allen großen Städten brennen die Synagogen. Deutsches Eigentum ist nicht gefährdet" (TG, 10.11.1938).

Hitler hatte sich, wie mehrfach überliefert ist, unmittelbar nach seiner Unterredung mit Goebbels in seine Wohnung am Prinzregentenplatz begeben, bevor er gegen Mitternacht an der Vereidigung der SS-Verfügungstruppen und -Totenkopfverbände vor der Feldherrnhalle teilnahm. ${ }^{153}$ Die Rückkehr in seine Wohnung erscheint äußerst plausibel, verschaffte sie ihm doch ein scheinbares Alibi. „Je mehr Anrufe von Zerstörungen jüdischer Geschäfte und Synagogen eintrafen, auch aus anderen Städten des Reiches, um so erregter und wütender wurde Hitler", schrieb dessen Adjutant in seinen Memoiren über Hitlers Reaktion in der Pogromnacht. ${ }^{154}$ Bezeichnenderweise enthält dieser Satz des Augenzeugen Below, der der Entlastung seines „Führers“ dienen sollte, kein direktes Objekt der Empörung, sondern suggeriert, das reichsweite Wüten habe Hitler aufgebracht. Es ist allerdings anzunehmen, daß Hitlers Wut und Erregung sich gegen das Judentum richteten - nicht gegen die Ausschreitungen.

151 Wieviele Juden verhaftet wurden, läßt sich nicht exakt nachweisen, da für das Konzentrationslager Sachsenhausen keine gesicherten Zahlen vorliegen. Fest steht, daß nach Dachau 10911 und nach Buchenwald 9845 Juden verbracht wurden. Meier Schwarz schätzt die Zahl der nach Sachsenhausen deportierten Personen auf ca. 10000; Pollmeier, Inhaftierung, S.110f., hingegen auf ca. 6000. Meier Schwarz, Die „Kristallnacht“Lüge, URL: <http://www.schoah.org/schoah/kristallnacht.htm> [30.11. 2010]. Vgl. auch Döscher, „Reichskristallnacht“, S.120f.

152 Diese Goebbels-Aussage geht auf den stv. Gauleiter von München-Oberbayern, Otto Nippold, zurück und ist im Bericht des Obersten Parteigerichts vom 13.2.1939 an Göring überliefert, in: IMG 32, Dok.3063-PS, S.29. Das Parteigericht kam aufgrund Goebbels’ Ausspruchs zu dem Schluß, wie der Bericht an Göring beweist, daß die „Führung" mit der Tötung von Juden einverstanden war und empfahl eine Niederschlagung der Verfahren außer im Falle von „Rassenschande“, d.h. Vergewaltigung: „In diesem Zeitpunkt hätten sich die meisten Tötungen durch eine ergänzende Anordnung noch verhindern lassen. Wenn dies nicht geschah, so muss aus dieser Tatsache wie aus der Äußerung an sich schon der Schluß gezogen werden, daß der schließliche Erfolg gewollt, mindestens aber als möglich und erwünscht in Rechnung gestellt wurde. Dann hat aber der einzelne Täter nicht nur den vermeintlichen, sondern den zwar unklar zum Ausdruck gebrachten, aber richtig erkannten Willen der Führung in die Tat umgesetzt. Dafür kann er nicht bestraft werden.“

153 Aussage Ebersteins vom 3.8.1946, in: IMG 20, S.320; Below, Hitlers Adjutant, S. 136.

154 Below, Hitlers Adjutant, S. 136. 
Am nächsten Tag, dem 10. November 1938, suchte Goebbels, nachdem er eine Flut von Berichten zur Kenntnis genommen hatte, Hitler in dessen italienischem Stammrestaurant in München zum Bericht auf: „In der Osteria erstatte ich dem Führer Bericht. Er ist mit allem einverstanden. Seine Ansichten sind ganz radikal und aggressiv“ (TG, 11.11.1938). ${ }^{155}$ Auch dieser Eintrag belegt deutlich, daß Hitler der eigentlich Verantwortliche für den Pogrom war und Goebbels Befehlsempfänger, der den Vollzug des „Führer-Befehls“ zu melden hatte. Goebbels notierte daher auch mit keinem Wort, daß er sich Sorgen machte, wie Hitler wegen des Pogroms reagieren würde. Derartige Gedanken waren überflüssig, denn Hitler war, wie Goebbels dezidiert festhielt, „mit allem einverstanden“, was in der Nacht zuvor passiert war, und fand die Aktion „tadellos“ (TG, 11.11.1938).

Die einzige Frage, die Goebbels und Hitler an diesem Vormittag und Mittag beschäftigte, war die, ob die Ausschreitungen weitergehen sollten: „Ich überlege mit dem Führer unsere nunmehrigen Maßnahmen. / Weiterschlagen lassen oder abstoppen? / Das ist nun die Frage“ (TG, 10.11.1938). Goebbels setzte schließlich „eine Verordnung auf Abschluß der Aktionen auf“, die er damit begründete, daß es „nun gerade genug“ sei und daß andernfalls „die Gefahr“ bestünde, „daß der Mob in Erscheinung tritt“ (TG, 11.11.1938). „Mit kleinen Änderungen“ billigte Hitler mittags oder am frühen Nachmittag des 10. November Goebbels’ „Erlaß betr. Abbruch der Aktionen“. Goebbels gab die Anweisung daraufhin „durch Presse und Rundfunk heraus“ (TG, 11.11.1938). ${ }^{156}$ Ähnliche Anordnungen Goebbels’ ergingen auch an alle Gauleiter, ${ }^{157}$ denen allerdings die Schäden und die geplanten gesetzlichen Regelungen deutlicher genannt wurden, und an die Polizei. Goebbels berichtet weiter, daß Hitler nun „zu sehr scharfen Maßnahmen gegen die Juden schreiten" wolle (TG, 11.11.1938).

Am Morgen des 12. November notierte Goebbels stolz das von ihm verfügte Ende des Pogroms: „Die Lage im Reich hat sich allgemein beruhigt. Es ist kaum noch etwas vorgekommen. Mein Aufruf hat Wunder getan. Die Juden können mir obendrein noch dankbar sein“ (TG, 12.11.1938). Die von Goebbels eingeforderte Dankbarkeit der Juden wirkt äußerst zynisch, da er die Pogrome auf Weisung Hitlers entfacht hatte, aber auch nicht völlig abwegig. Denn als beispielsweise der Münchener Oberbürgermeister Karl Fiehler in der nächsten längeren Ratsherrensitzung den Aufruf von Goebbels gegen weitere Einzelaktionen erwähnte, kam aus der Reihe der Münchener Ratsherren, wie das Sitzungsprotokoll ausweist, der Zwischenruf „Schade!“158 Goebbels dürfte die Stimmung am besten gekannt haben und ging offenbar nicht zu Unrecht davon aus, daß viele Partei-, SA- und SS-Mitglieder die Gewalttätigkeiten gegen Jüdinnen und Juden nicht beendet hätten, wenn ihnen dies nicht ausdrücklich befohlen worden wäre. Angesichts

155 Die Chronologie Adams, Wie spontan, S.79f., ist zu modifizieren: Adam nahm irrtümlich an, beide, Hitler und Goebbels, seien am Vormittag des 10.11.1938 wieder in Berlin eingetroffen, da Hitler bekanntlich am Abend des 10.11.1938 in München im Führerbau eine Rede vor ca. 400 Journalisten hielt; vgl. Treue, Rede Hitlers, S. 175-191.

156 Goebbels’ Aufruf ist abgedr. in: Kropat, „Reichskristallnacht“, Dok. 23a, S.233.

157 Siehe Kropat, „Reichskristallnacht“, Dok. 23b, S. 233.

158 Niederschrift über die 30. Sitzung der Ratsherren der Hauptstadt der Bewegung vom 15.11.1938, StadtAM, Ratssitzungsprotokolle, Jg. 1938, Nr.711/1, Tagesordnungspunkt 20. 
mehrerer Hundert Toter, Hunderter in Brand gesteckter Synagogen, Tausender verwüsteter oder geplünderter ${ }^{159}$ Geschäfte und Wohnungen zeigt der Wunsch des nicht namentlich genannten Münchener Ratsherrn, daß es in der NSDAP unzählige radikale Antisemiten gab, die in ihrem Judenhaß Goebbels gleichkamen.

Vorgeschichte, Vorwand und Initiierung der Pogrome sind dargelegt, das Ausmaß angedeutet worden. Befehlswege und Ablauf der Ereignisse, die Rolle der NSDAP, SA, SS sind intensiv in zahlreichen Studien, auch auf Regional- und Lokalebene, untersucht worden, so daß an dieser Stelle auf eine Darstellung des eigentlichen Geschehens verzichtet werden kann. Zu klären bleibt, ob Goebbels Hinweise zu den Tätern der antisemitischen Gewalt liefert. In einigen Fällen gab Goebbels sehr genaue Beschreibungen von den Anstiftern und Gewalttätern dieser Nacht. Über eine Tätergruppe berichtete Goebbels in seinem Tagebucheintrag vom 10. November 1938 auffälligerweise gleich viermal: 1. „Diesen feigen Mord dürfen wir nicht unbeantwortet lassen. Mal den Dingen ihren Lauf lassen. Der Stoßtrupp Hitler geht gleich los, um in München aufzuräumen. Das geschieht denn auch gleich. Eine Synagoge wird in Klump geschlagen. Ich versuche sie vor dem Brand zu retten. Aber das mißlingt.“ 2. „Mit Wagner zum Gau. Ich gebe noch ein präzises Rundschreiben heraus, in dem dargelegt wird, was getan werden darf und was nicht. Wagner bekommt kalte Füße und zittert für seine jüdischen Geschäfte. Aber ich lasse mich nicht beirren. Unterdeß [!] verrichtet der Stoßtrupp sein Werk. Und zwar macht er ganze Arbeit.“ 3. „Ich will ins Hotel, da sehe ich den Himmel blutrot. Die Synagoge brennt. Gleich zum Gau. Dort weiß noch niemand etwas. Wir lassen nur soweit löschen, als das für die umliegenden Gebäude notwendig ist. Sonst abbrennen lassen. Der Stoßtrupp verrichtet fürchterliche Arbeit.“ 4. „Schaub ist ganz in Fahrt. Seine alte Stroßtruppvergangenheit erwacht" (TG, 10.11.1938). ${ }^{160}$

159 Plünderungen kamen in großem Ausmaß vor, wenngleich die NSDAP diese verboten hatte und anschließend zu verschleiern suchte; vgl. beispielsweise Kellerhoff, „Kristallnacht", S.34-36. Heydrich hatte in einem Fernschreiben in der Pogromnacht angeordnet: „Geschäfte und Wohnungen von Juden dürfen nur zerstört, nicht geplündert werden." Blitz-Fernschreiben des SS-Gruppenführers und Chefs der Sicherheitspolizei Heydrich an alle Staatspolizeileit- und Staatspolizeistellen und SD-Ober- und Unterabschnitte, 10.11.1938, 1.20 Uhr, in: IMG 31, Dok.3051-PS, S.516. Siehe hierzu auch die entsprechenden Anordnungen, Verfügungen und Erlasse in: Walk, Sonderrecht, S.253, 260, 263. Einer vertraulichen Anordnung des Stellvertreters des Führers, Stabsleiter Martin Bormann, Nr. 189/38, vom 23.11.1938 zufolge, sollten die Dienststellen der Partei und ihrer Gliederungen Wertgegenstände, die „zum Schutze deutschen Volksvermögens $[\ldots]$ sichergestellt“ worden seien, „unverzüglich an die nächste Dienststelle der Geheimen Staatspolizei“ abgeben. Österreichisches Staatsarchiv, AdR, 04: Inneres/Justiz, Reichskommissar für die Wiedervereinigung Österreichs mit dem Deutschen Reich, Bürckel/Materie, Mappe 4210, Karton 193. Auch Goebbels war über derartige Eigentumsdelikte informiert, wie sein Tagebuch belegt, in das er schrieb: „Es sind bei den Judenaktionen einige Plünderungen vorgekommen", TG, 30.11.1938.

${ }^{160}$ Die vier Passagen waren - wie der gesamte Eintrag, der in den 80er Jahren noch nicht bekannt war - in der Fragmente-Ausgabe von 1987, Fröhlich, Tagebücher. Sämtliche Fragmente, nicht enthalten, die ersten drei davon wurden zuerst im Nachrichtenmagazin „Der Spiegel“ (Nr.29, 13.7.1992, S. 126) veröffentlicht. In der mangelhaften Publi- 
Die viermalige Erwähnung des „Stoßtrupp“ ist erstaunlich und deutet auf eine besondere Rolle bei dem Pogrom in München hin. Gegründet wurde der „Stoßtrupp Adolf Hitler“ im Frühjahr 1923 als Leibwache Hitlers. Bei Hitlers Putschversuch am Abend des 8. November 1923 hatte der Stoßtrupp die Ein- und Ausgänge des Bürgerbräukellers abgeriegelt und Druckerpresse, Inventar und Akten der sozialdemokratischen Zeitung „Münchener Post“ demoliert. Geplant war auch, deren Schriftleiter Erhard Auer, der zugleich bayerischer SPD-Vorsitzender war, zu verschleppen, doch Auer konnte sich dem Zugriff entziehen, so daß die Stoßtruppmänner seinen Schwiegersohn als Geisel nahmen. ${ }^{161}$ Am Morgen des 9. November 1923 hatte der Stoßtrupp versucht, aus dem Polizeipräsidium verhaftete Putschisten zu befreien. Wenig später war der Trupp in das Münchener Rathaus eingedrungen und hatte laut Gerichtsurteil „den Bürgermeister Schmi[d] und einige Stadträte der sozialistischen und kommunistischen Partei“ als Geiseln genommen und verschleppt, wobei beabsichtigt war, „diese Geiseln zu erschießen, wenn auf den Zug von Seiten der Reichswehr oder Landespolizei geschossen werden sollte“.162 Die Stoßtruppmänner bewachten offenbar während des Marsches in Richtung Feldherrnhalle die Geiseln. Im April 1924 wurden daher infolge des gescheiterten Putsches 38 Stoßtruppmitglieder wegen Hochverrats $\mathrm{zu}$ milden Haftstrafen verurteilt, einige in Abwesenheit, der Stoßtrupp selbst wurde verboten. ${ }^{163}$ Nach der Neugründung der NSDAP Anfang 1925 übernahm die nun geschaffene Stabswache, die noch im selben Jahr in Schutzstaffel (SS) umbenannt wurde, die Funktionen des früheren Stoßtrupps. ${ }^{164}$ Nach 1924 scheint somit der „Stoßtrupp Hitler" nicht mehr existiert zu haben.

Die oben zitierten Passagen aus Goebbels' Tagebuch verleiteten eine „revisionistische“ Autorin zu der Behauptung, es handele sich bei diesem Text um eine „Fälschung“: 1938 habe es keinen „Stoßtrupp Hitler“ mehr gegeben, also „hätte Goebbels daher" eine solche „Bemerkung [...] gar nicht machen können“.165

kation des Goebbels-Tagebuchs von Irving, Der unbekannte Dr. Goebbels, weichen die vier Passagen nur geringfügig vom Original ab, bei Reuth, Goebbels. Tagebücher, fehlen sie gänzlich.

161 Walter, Antisemitische Kriminalität, S. 122.

162 Urteil des Volksgerichtes für den Landgerichtsbezirk München I gegen „Berchtold Josef und 39 Genossen", 23.4.1924; IfZ, Archiv, Fa 523, Zitate S.157cc; Kallenbach, Landsberg, S. 22-29; Broszat, Machtergreifung, S.32-34; Höhne, Der Orden, S. 25.

163 Urteil des Volksgerichtes für den Landgerichtsbezirk München I gegen „Berchtold Josef und 39 Genossen", 23.4.1924; IfZ, Archiv, Fa 523.

164 Vgl. Kallenbach, Landsberg, S. 8-12, 19; Wegner, Waffen-SS, S.79f.; Koehl, The Black Corps, S.12-17; Höhne, Der Orden, S.23-27; Buchheim, Die SS, S.30f.; Reitlinger, The SS, S. 10-14; d'Alquen, Die SS, S. 6; Volz, Geschichte der NSDAP, S. 10.

165 Auch ignorierte Weckert bewußt das Faktum, daß Goebbels' Tagebucheinträge jeweils die Geschehnisse des Vortags wiedergeben. So zweifelte sie den Tagebucheintrag vom 10.11.1938, in dem Goebbels das Befinden vom Raths am Mittag des 9.11. beschrieb, mit dem Argument an, vom Rath sei „bereits gestorben“, oder denjenigen Eintrag vom 9.11., in dem Goebbels die Synagogenbrände des 7. und 8.11. erwähnte, weil ihr offenbar nicht bekannt war, daß es solche schon am 8.11.1938 gegeben hatte. Weckert, Dr. Joseph Goebbels, S. 196-203. Ebenfalls der Entlastung Hitlers und des NS-Regimes wegen bestritt Irving die Glaubwürdigkeit der Goebbels-Tagebücher; siehe zu beiden: Evans, Der Geschichtsfälscher, S. 75-96. 
Doch auch diese Textstellen sind echt. Da Goebbels den „Stoßtrupp“ in diesem einen Eintrag viermal nannte, ist die mögliche Argumentation unhaltbar, Goebbels habe sich hier verschrieben oder geirrt. Wen meinte Goebbels also, wenn er 1938 den „Stoßtrupp Hitler“ scheinbar wieder auferstehen ließ?166

Goebbels liefert den Schlüssel zum Verständnis selbst, indem er notierte, daß Julius Schaubs „alte Stoßtruppvergangenheit erwach"“ (TG,10.11.1938) sei. Schaub, Hitlers persönlicher Adjutant und dessen „rechte Hand“, 167 war eines der prominentesten Mitglieder des „Stoßtrupps Adolf Hitler“, 168 die mehrheitlich gemeinsam mit Hitler in Landsberg eingesessen hatten und ihm seit dieser Zeit ganz besonders treu ergeben und eng verbunden waren. Nach der Freilassung und dem Wiederaufbau der NSDAP übertrug Hitler alle Aufgaben, die besonderes Vertrauen erforderten, ehemaligen Stoßtruppmännern: Julius Schaub wurde 1925 Hitlers „ständiger Begleiter“, Emil Maurice Hitlers Chauffeur, Josef Berchtold 1926 der erste „Reichsführer SS“ ${ }^{169}$ Der Stoßtrupp bildete auch den Kern der 1925 geschaffenen „Schutzstaffel“ (SS). ${ }^{170}$ Nach der Machtübernahme 1933 gehörten die Stoßtruppmänner zur nationalsozialistischen Prominenz, der Stoßtrupp bestand als Traditionsverband fort, sechs seiner Mitglieder saßen im Reichstag. ${ }^{171}$ Julius Schaub wurde Hitlers „Persönlicher Adjutant“ und blieb unter all den Angestellten der einzige, der von Hitler persönlich bezahlt wurde. ${ }^{172}$ Schaub organiserte Hitlers Tagesablauf, erledigte finanzielle Aufträge für ihn und war so gut wie täglich mit seinem „Führer“ zusammen, in der Regel schon beim Frühstück. ${ }^{173}$ Er war über all die Jahre Hitlers engster und treuester Mitarbeiter. Bis zuletzt erfüllte

166 Dieser Frage wandte sich die Forschung bisher nicht zu, vielleicht, weil in den bisherigen Untersuchungen überwiegend die Fragmente- oder die Reuth-Ausgabe benutzt worden waren, die die Textstellen nicht enthalten, da der entsprechende Band 6 der Edition von Elke Fröhlich noch nicht vorgelegen hatte. Dies gilt für Longerich, Politik; Kropat, „Reichskristallnacht“; Döscher, „Reichskristallnacht“; Heusler/Weger, „Kristallnacht". Allerdings ist auch bei neueren Forschungen festzustellen, daß mit den alten Ausgaben gearbeitet wurde, z.B. Kley, Hitler and the Pogrom, S. 87-112, oder Gilbert, Kristallnacht. Friedländer, der diesen Eintrag der Goebbels-Tagebücher nach dem "Spiegel“ zitiert, Das Dritte Reich und die Juden, Bd.I, S.294, ließ die Stoßtrupp-Passagen weg. Kershaw, Hitler, Bd.2, S. 196, verwies nur darauf, daß die „Tradition“ des Stoßtrupps „bis in die heißen Tage vor dem ersten Putsch und zu den damaligen Wirtshausschlägereien zurückreichte". Barth, Goebbels und die Juden, S.136, zitiert zwei der Stoßtrupp-Passagen unreflektiert in den Anmerkungen.

167 So Kershaw, Hitler, Bd.2, S. 198.

168 In der NS-Broschüre „Daten der Geschichte der NSDAP“, die in vielen Auflagen erschien, wurden Julius Schaub, Emil Maurice und Karl Fiehler als die prominentesten der 40 Mitglieder des „Stoßtrupp Hitler“ genannt, die 1924 infolge des Putsches verurteilt worden waren; vgl. Volz, Geschichte der NSDAP, S. 10.

169 Vgl. Statisten in Uniform, S.32f., 405 f., 547.

170 Vgl. Koehl, The Black Corps, S. 21; Höhne, Der Orden, S.23f., $27 f$.

171 Mitglieder des Reichstags waren: Josef Berchtold (SA-Gruppenführer), Hanns Bunge (SABrigadeführer), Karl Fiehler (SS-Gruppenführer, Oberbürgermeister Münchens), Friedrich Geißelbrecht (SA-Oberführer), Emil Maurice (SS-Standartenführer, Bayerischer Landeshandwerksmeister) und Julius Schaub (SS-Gruppenführer und „Persönlicher Adjutant des Führers"). Vgl. Statisten in Uniform, S.32f., 73f., 138f., 171, 405 f., 547.

172 Rose, Schaub, S. 118.

173 IfZ, Archiv, ZS 137, Bl.9 (Interrogation No.292, Schaub, 7.12.1946); Rose, Schaub, S. $121,135 f$. 
er gehorsamst Hitlers Wünsche und vernichtete noch im April 1945 weisungsgemäß zahlreiche Dokumente, die sich in den Panzerschränken in der Reichskanzlei und deren Bunker, in der Münchener Privatwohnung und auf dem Berghof befunden hatten.

Anläßlich der Feierlichkeiten am 8./9. November eines jeden Jahres hatten sich die Mitglieder des Stoßtrupps zu einem Kameradschaftsabend getroffen. ${ }^{174}$ Nachweisbar sind auch gemeinsame Ausflüge der Stoßtruppmänner nach Stettin, wo vom 24.-26. April 1936 ein „Treffen des Stoßtrupp Hitler 1923“ stattgefunden hatte, über das Goebbels informiert war, ${ }^{175}$ oder am 8. November 1938 zur Festung nach Landsberg, ${ }^{176}$ wo ein Großteil von ihnen 1924 inhaftiert war. ${ }^{177}$ Die Stoßtruppmänner hatten also ein enges Verhältnis und waren einander verbunden, was auch daran ersichtlich ist, daß im Falle von schweren Erkrankungen oder Unfällen eines Trupp-Mitgliedes die anderen schriftlich aufgefordert wurden, ihren Kameraden in der Klinik zu besuchen. ${ }^{178}$ Anfangs wurden die Mitglieder des Stoßtrupps von der Obersten SA-Führung betreut, später vom Stoßtruppkameraden Friedrich Geißelbrecht im „Amt für den 8./9. November 1923“, das Christian Weber leitete. ${ }^{179}$ Alljährlich hatten die Stoßtruppmänner anläßlich des Jahrestages des Putschversuchs auch bestimmte Aufgaben: Begrüßung der angereisten Blutordensträger, Verteilung der Freifahrtscheine für die öffentlichen Verkehrsmittel und der Verpflegungsausweise, Ausweis-, Dienstanzugs- und Zugangskontrollen zur Abendveranstaltung am 8. November im Bürgerbräukeller, Aufstellung des Marschblocks der Blutordensträger am Morgen des 9. November. ${ }^{180}$

174 Vgl. Einladungsschreiben aus den Jahren 1933 bis 1936 bzw. 1937-1943 an Karl Fiehler in: StadtAM, Bürgermeister und Rat, Nr.458/2 bzw. Nr.458/3 sowie Nr.446/2 und 452/19.

175 Anläßlich dieses Treffens 1936 in Stettin wurde die damalige Zeitung der Landsberger Häftlinge von 1924 im Faksimiledruck an die früheren Kameraden ausgehändigt. Von insgesamt 100 Exemplaren erhielt eines Hitler, eines Goebbels; siehe IfZ, Bibliothek, Fobke, Stoßtrupp.

176 Einladungsschreiben Friedrich Geißelbrechts, Amt für den 8./9. November 1923, im Namen des „Stoßtrupp Adolf Hitler 1923“ an „alle Stoßtruppkameraden“, 1.11.1938, StadtAM, Bürgermeister und Rat, Nr.458/3.

177 Von den 25 „Festungskameraden“ Hitlers waren 22 Stoßtruppmänner, die drei weiteren Mithäftlinge waren Rudolf Heß, Hermann Kriebel, Dr. Friedrich Weber. Der Haft hatten sich 16 der 38 verurteilten Stoßtruppmänner durch Flucht entzogen. Mit Hitler saßen folgende Stoßtruppler ein: Wilhelm Briemann, Josef Feichtmayr, Otto Feichtmayr, Karl Fiehler, Berthold Fischer, Hermann Fobke, Friedrich Geißelbrecht, Josef Gerum, Johann Haug, Paul Hirschberg, Gerhard Friedrich Hoff, Hans Kallenbach, Hans Eduard Krüger, Wilhelm Laforce, Johann Mahr, Emil Maurice, Otto Wolfgang Reichart, Alois Rosenwink, Julius Schaub, Ludwig Schmied, Edmund Schneider, Johann Schön. Liste der „Festungskameraden des Führers“, erstellt 1935, in: StadtAM, Bürgermeister und Rat, Nr.458/2, o. P.; Urteil des Volksgerichtes für den Landgerichtsbezirk München I gegen „Berchtold Josef und 39 Genossen“, 23.4.1924; IfZ, Archiv, Fa 523, S. 157n-q.

178 Aufforderungsschreiben des Amts für den 8./9. November 1923 an die Stoßtruppmitglieder, den „Kameraden Albert Linder“ in der Klinik zu besuchen, 12.10.1937; StadtAM, Bürgermeister und Rat, Nr.458/3.

179 Vgl. diverse Schreiben an Karl Fiehler in: StadtAM, Bürgermeister und Rat, Nr.458/2 und 458/3; vgl. auch Berg, Korruption, S.52-55.

180 „Befehl Nr.2“ des Amts für den 8./9. November 1923, Christian Weber, an die Stoßtruppmitglieder, 1.11.1937; StadtAM, Bürgermeister und Rat, Nr.458/3. 
Dieselben Funktionen hatte der Stoßtrupp im Jahre 1938, wie aus einer Notiz der Persönlichen Adjutantur Hitlers hervorgeht, die auch dem Propagandaministerium zugeleitet zu worden scheint. ${ }^{181}$ „Die alten Kämpfer begrüßen mich sehr herzlich“ (TG, 9.11.1938), hatte Goebbels 1938 am Morgen nach der Veranstaltung im Bürgerbräukeller notiert, was belegt, daß ihm bewußt war, um wen es sich bei den Türstehern handelte. Die Mitglieder des Stoßtrupps, zum Teil sehr prominente Nationalsozialisten und Reichstagskollegen von Goebbels, begriffen diese Tätigkeiten als ehrenhafte Aufgabe, und so waren sie von der Partei auch gemeint. Denn die Stoßtruppmänner waren die Ehrengäste der Versammlung im Bürgerbräukeller. Auf der Sitzordnung für den „Kameradschaftsabend“ am 9. November 1938 war eigens gekennzeichnet, wer dem Stoßtrupp angehört hatte. Von den ca. 400 Teilnehmern der Veranstaltung gehörten genau 39 dem Stoßtrupp an, er stellte also ein Zehntel aller Anwesenden, die fast alle in Hitlers unmittelbarer Nähe saßen. 182

Zudem besaß der Stoßtrupp einen eigenen Dienstanzug, welcher der Uniform der Blutordensträger glich, sich von dieser aber durch die Armbinde „Stoßtrupp Adolf Hitler“ und die „Stoßtruppmütze mit Totenkopf“ unterschied. ${ }^{183}$ Die Stoßtruppmänner waren also eindeutig identifizierbar. Auch in der zeitgenössischen Presse wurde der Stoßtrupp erwähnt. ${ }^{184}$ Wenn Goebbels also schrieb, daß der „Stoßtrupp“ losgegangen sei, um „in München aufzuräumen“, daß infolgedessen eine Synagoge,,in Klump geschlagen“"und angezündet worden sei (TG, 10.11.1938), so kann Goebbels niemand anderes gemeint haben, als die seinerzeit in München anwesenden, namentlich bekannten Mitglieder des „Stoßtrupps Adolf Hitler“. 185

181 „Programm für die Feierlichkeiten anläßlich des 8. und 9. November 1938“ mit handschriftlichem Vermerk „Prop.Min.“, BArch, NS 10/45, Bl.144.

182 „Sitzordnung im Festsaal des Alten Rathauses in München am 9.November 1938“, StadtAM, Bürgermeister und Rat, Nr.458/3. Neben dem Urteil gegen den Stoßtrupp (Urteil des Volksgerichtes für den Landgerichtsbezirk München I gegen „Berchtold Josef und 39 Genossen“, 23.4.1924; IfZ, Archiv, Fa 523, S. 157n-q) existieren auch in den Akten der Persönlichen Adjutantur des Führers und Reichskanzlers (BArch, NS 10/134, Bl.135) sowie in den Akten Fiehlers (StadtAM, Bürgermeister und Rat, Nr.458/2 und 458/3) Listen der Stoßtruppmänner, die weitgehend übereinstimmen.

183 „Dienstanzug des Stoßtrupps am 8./9. November 1938“, BArch, NS 10/45, Bl.145. Zur Uniform der Blutordensträger siehe Zeitungsausschnitte VB, 8.10.1937 und 30.10.1937 in: StadtAM, Bürgermeister und Rat, Nr.458/3.

${ }^{184}$ In der „Deutschen Allgemeinen Zeitung“ stand beispielsweise in einem Artikel vom 9.11.1938, S.1, über Hitlers Rede am Vortag im Bürgerbräukeller: „In nächster Nähe des Rednerpultes steht der Tisch, um den sich die Kämpfer des Stoßtrupps Hitler sammeln. Karl Fiehler ist unter ihnen, [...]“. Derselbe Text erschien am selben Tag auf S.1 der „Berliner Börsen-Zeitung“, ging also auf einen DNB-Text zurück: DNB-Meldung „Der Sieg des Glaubens“, Nr.70, 8.11.1938, 22.00 Uhr, Bl.46-48. Auch anläßlich der Beschreibung des Marsches wurde der Stoßtrupp erwähnt. Vgl. Zeitungsausschnittsammlung „,zu den Jahrestagen des Hitler-Putsches vom 9.November 1923“, BArch, R 55/21172.

185 Neben den bereits erwähnten 22 Stoßtruppmännern, die mit Hitler in der Festung Landsberg inhaftiert waren, finden sich in der Sitzordnung der Versammlung am 9.11.1938 im Alten Rathaussaal noch folgende 17 Namen von Stoßtruppmitgliedern: Walter Baldenius, Josef Berchtold (der Kommandant 1923), Hanns Bunge, Emil Dietl, Wilhelm Dirr, Julius v. Engelbrechten, Fritz Fischer, Josef Fleischmann, Johann Frosch, 
Abgesehen von diesem Tagebucheintrag Goebbels' ist bislang offenbar keine Quelle aufgefunden worden, die die Täterschaft dieser prominenten Nationalsozialisten bestätigt. Die fotographische Sammlung des Fotostudios Heinrich Hoffmann, die möglicherweise belegen könnte, welche der Stoßtruppmitglieder persönlich für die Inbrandsetzung der Synagoge oder für die Verwüstung von jüdischen Geschäften in München verantwortlich gemacht werden müßten, enthält keine Tatfotos. Die letzten Bilder der Fotostrecken vom 9. November 1938 zeigen die Vereidigung der SS-Verfügungstruppen und -Totenkopfverbände vor der Feldherrnhalle gegen Mitternacht, die folgenden die zerstörten Synagogen und Geschäfte am Morgen des 10. November 1938. ${ }^{186}$ Dies deutet auf eine Filterung der Bildkartei bei Kriegsende hin.

Obgleich ein endgültiger Nachweis der Verantwortung des Stoßtrupps für einige schwere Verwüstungen und die Zerstörung der Synagoge „Ohel Jakob“ in der Herzog-Rudolf-Straße in München noch aussteht, muß die viermalige Erwähnung bei Goebbels als zusätzliches Indiz dafür betrachtet werden, daß Hitler den Befehl für den Pogrom gegeben hat und letztlich für die Morde und exzessiven Verwüstungen die Verantwortung trägt. Denn die Angehörigen des Stoßtrupps, die schon $1923 \mathrm{ihr}$ Leben für Hitler zu geben bereit waren, fühlten sich wie kaum eine zweite Truppe an das Wort Hitlers gebunden. ${ }^{187}$ Albert Speer bezeichnete 1942 eben jenen von Goebbels erwähnten Stoßtruppmann Julius Schaub als den „treuesten Gefolgsmann des Führers“. 188 Daß sich diese alten, erfahrenen Aktivisten nur dem „Führer“ allein verpflichtet fühlten, deutet sich in der Notiz von Goebbels an, er habe sich darum bemüht, daß die Synagoge nicht in Brand gesetzt werde. Doch die Stoßtruppmänner ließen sich von Goebbels offensichtlich nicht zurückhalten. Im Tagebuch hielt er fest, daß er versucht habe, die Synagoge „vor dem Brand zu retten. Aber das mißlingt" (TG, 10.11.1938). ${ }^{189}$ Diese Angabe des Propagandaministers ist nicht unwahrscheinlich und könnte auf eine Radikalisie-

Wilhelm Fuchs, Walther Hewel, Wilhelm Kaiser, Florian Kastner, Albert Lindner, Heinz Pernet, Hans Schultes, Fritz Schwerdtel. „Sitzordnung im Festsaal des Alten Rathauses in München am 9. November 1938“, StadtAM, Bürgermeister und Rat, Nr.458/3.

186 Das Bildarchiv enthält knapp 600 Fotos aus dem Zeitraum 8.-10.11.1938 nachmittags; das Foto Nr.21977 zeigt die Vereidigung der SS in der Nacht zum 10.11., das folgende mit der Nr.21978 die ausgebrannte Synagoge "Ohel Jakob“ in der Herzog-RudolfStraße. Fotoarchiv Heinrich Hoffmann, Bayerische Staatsbibliothek München, OnlineBilddatenbank, <http://fachkataloge.bsb-muenchen.de/img/hoff-21977.jpg >, <http:// fachkataloge.bsb-muenchen.de/img/hoff-21978.jpg > [30.11.2010].

187 Vgl. die pathetische Schilderung der Gründung und Vereidigung des Stoßtrupps Hitler bei Kallenbach, Landsberg, S. 8, 13, einem Mitglied des Stoßtrupps Hitler.

188 Albert Speer in einem Geburtstagstelegramm an Schaub 1942, zit. nach Machtan, Hitlers Geheimnis, S.200.

189 Goebbels hatte keine Bedenken, Synagogen dem Erdboden gleichzumachen, aber offenbar befürchtete er, daß der Brand auf andere Gebäude übergreifen könnte, dies geht aus einer Notiz einige Tage später hervor: „Im Übrigen sind wir bei den Bränden großen Gefahren wegen der umliegenden Stadtviertel entgangen. Gottseidank!“ TG, 15.11.1938. Der mögliche Einwand, Goebbels habe, als er schrieb, eine Synagoge vor dem Brand retten zu wollen, an dieser Stelle eine Lüge in die Welt gesetzt, überzeugt nicht, da er sich im selben Eintrag als Anstifter des Pogroms und einiger Zerstörungen in Berlin zu erkennen gegeben hatte. 
rung im Laufe der Nacht hinweisen. Der Stoßtrupp, einmal losmarschiert, hätte sich vermutlich von niemand anders als Hitler zurückrufen lassen, doch dieser unternahm nichts dergleichen. Möglicherweise handelten die alten Stoßtruppkameraden also nicht auf Goebbels' Brandrede hin, sondern auf eine direkte Anweisung Hitlers, der seit dem Tode Ernst vom Raths um 16.30 Uhr genügend Zeit gehabt hätte, Befehle an seine alten Gefolgsleute zu erteilen, und der mit Schaub und sieben weiteren ehemaligen Stoßtruppmitgliedern im Festsaal des Alten Rathauses an einem Tisch saß. ${ }^{190}$ Zumindest wird Hitler aber den „Alten Kämpfern“ signalisiert haben, daß er mit einer Beteiligung des Stoßtrupps an den Ausschreitungen einverstanden war. Denn Schaub wäre ohne ein solches Signal sicherlich nicht aktiv geworden, hätte nicht versucht, in dieser brisanten Angelegenheit intuitiv den Willen Hitlers zu erfassen und eigenmächtig zu handeln, d.h. ihm „entgegen zu arbeiten". ${ }^{191}$ Ein halbes Jahr zuvor hatte Schaub in einer gänzlich unbedeutenden Angelegenheit einen Wunsch Hitlers selbständig umzusetzen versucht und sich den Zorn seines „Führers“ zugezogen. Damals, am 29. Mai 1938 auf dem Gauparteitag in Dessau, hatte Hitler die Beteiligung der Hitler-Jugend am Marschzug kritisiert, woraufhin Schaub ohne Rücksprache die Kolonnen der NS-Jugendverbände abschwenken ließ. Daraufhin war Hitler äußerst wütend geworden und degradierte seinen persönlichen Adjutanten wegen dieser Eigenmächtigkeit vom SS-Gruppenführer zum SS-Brigadeführer. Trotz Fürsprachen von Goebbels, Göring und Wiedemann war Hitler unerbittlich, und Schaub, wie Goebbels überliefert, „ganz gebrochen“ und „weint [e]“" (TG, 3.6.1938). 192

Angesichts möglicher schwerwiegender Konsequenzen für das NS-Regime ist auszuschließen, daß Schaub und der Stoßtrupp sich ohne entsprechende Anweisung oder Signalisierung durch Hitler am Pogrom maßgeblich beteiligt hätten. Die Rolle des „Stoßtrupp Hitler“ beim Novemberpogrom in München bedarf also noch weiterer Untersuchungen. Möglicherweise war er auch an der Zerstörung jüdischer Geschäfte in der Nähe des Alten Rathauses beteiligt. ${ }^{193}$ Es scheint, als seien die Teilnehmer der Versammlung nach Ablegen ihrer Uniform ${ }^{194}$ randalierend durch die Stadt gezogen. ${ }^{195}$ Dies erklärt vielleicht auch, weshalb die Brand-

190 Es handelt sich um die Stoßtruppmänner Berchtold, Bunge, Fiehler, Geißelbrecht, Maurice, Pernet, Schaub und Schön; „Sitzordnung im Festsaal des Alten Rathauses in München am 9. November 1938“, StadtAM, Bürgermeister und Rat, Nr.458/3.

191 Kershaw, Hitler, Bd. 1, S. 665.

192 Vgl. TG, 30.5. 1938, 31.5.1938, 3.6.1938, und die Goebbels bestätigende Schilderung in den Schaub-Memoiren; Rose, Schaub, S. 166; vgl. auch BArch, SSO-Akte: Schaub, Julius, sowie Jordan, Erlebt, S. 172-174.

193 Vgl. Heusler/Weger, „Kristallnacht“, S.49-94 sowie Umschlagseiten.

194 Gauleiter Rudolf Jordan schrieb über die Situation nach der Goebbels-Rede und einigen Telefonaten in seinen Memoiren: Ich „zog mich in Zivil um und rüstete mich zu einem nächtlichen Bummel durch die Straßen der Innenstadt" - angeblich, um mögliche Ausschreitungen zu beobachten. Aber nur eine aktive Beteiligung würde den Kleidungswechsel und die Rüstung erklären, unabhängig davon, ob man Rüstung hierbei als materielle oder mentale Vorbereitung interpretiert. Jordan, Erlebt und Erlitten, S. $183 \mathrm{f}$.

195 Für diese Annahme spricht auch die Tatsache, daß mehrere prominente Nationalsozialisten nach dem Krieg erklärten, sie seien bei der Versammlung im Rathaussaal nicht dabei gewesen, mußten sie doch befürchten, für die Gewaltexzesse mitverantwortlich gemacht zu werden, beispielsweise der damalige Wirtschaftsminister Walther Funk 
stifter der Ohel-Jakob-Synagoge bisher nicht bekannt waren, offenbar wollte damals niemand die NSDAP-Prominenz beschuldigen. ${ }^{196}$

Für den einzigen bislang bekannten Mord in der Pogromnacht in München war jedoch nicht der Stoßtrupp verantwortlich, sondern eine kleine Gruppe von SA-Männern. Nach einem „Kameradschaftsabend“ des SA-Sturmes 22/I begaben sich einige SA-Leute in die Lindwurmstraße 185, wo zuvor SA-Männer die Schaufenster des jüdischen Geschäftes „Both \& Zeimer“ eingeworfen hatten und deswegen von Nachbarn zur Rede gestellt worden waren. Kurz nachdem die SA-Männer in die Wohnung des Ehepaars Both eingedrungen waren, tötete einer von ihnen, SA-Mann Hans Schenk, den jüdischen Kaufmann Chaim Both durch einen offenbar gezielten „Nahschuß“ in die Stirn. ${ }^{197}$ Der Mord an Both war auch deshalb von Bedeutung, da Both polnischer Staatsangehöriger war, und die Botschaft der Polnischen Republik daher beim Auswärtigen Amt gegen die Tat, die Untätigkeit der Polizei, die ausbleibende Obduktion etc. protestierte, worüber auch die Reichskanzlei unterrichtet wurde. ${ }^{198}$ Doch die Beschwerde der polnischen Diplomatie war kein Einzelfall. Die Novemberpogrome hatten zur Folge, daß „beim Auswärtigen Amt etwa 100 Proteste auswärtiger Vertretungen eingegangen “ waren, wie in einem Vermerk für Ribbentrop festgehalten worden war. ${ }^{199}$

Neben Hitler, dem Urheber der Pogrome, und dem Stoßtrupp gehörte auch Goebbels selbst zu den Tätern, wie er im Tagebuch deutlich werden läßt. Dies nicht allein wegen seiner Hetzrede oder wegen seines Fernschreibens an die Gauleitungen im Reichsgebiet. Eine Synagoge in Berlin wurde, das notierte Goebbels ganz konkret in sein Tagebuch, auf seine Initiative hin zerstört. Als Goebbels bekannt war, daß der Stoßtrupp, also die - in der Auffassung der Nationalsozialisten - ehrenwertesten Personen des Dritten Reiches, randalierend durch die Stadt zogen und seine Gauleiterkollegen Anweisungen gaben, entfaltete auch Goebbels für den Gau Berlin große antijüdische Aktivität. Er rief den Berliner Gaupropagandaleiter Werner Wächter an und befahl ihm die Zerstörung der Berliner Hauptsynagoge, ${ }^{200}$ wie er im Tagebuch eindeutig festgehalten hatte: „Ich weise Wächter in Berlin an, die Synagoge in der Fasanenstraße zerschlagen zu lassen. Er sagt nur dauernd: ,Ehrenvoller Auftrag““ (TG, 10.11.1938). Goebbels scheint auch eine Vollzugsmeldung verlangt zu haben, wie aus dem Tagebuch hervorgeht:

(Aussage vom 6.5.1946, in: IMG 13, S.131, 133f.), Hermann Göring (Aussage vom 14.3.1946, in: IMG 9, S.312) und der fränkische Gauleiter Julius Streicher (Aussage vom 29.4. 1946, in: IMG 12, S.355), obgleich diese Aussagen widerlegt worden sind: Die Anwesenheit Görings gab bereits Paul Körner in Nürnberg zu Protokoll (Aussage vom 12.3.1946, in: IMG 9, S. 186f.), diejenige Streichers hielt Goebbels im Tagebuch fest, TG, 10.11.1938.

196 Vgl. Heusler/Weger, „Kristallnacht“, S. 65.

197 Ausführlich dargestellt bei: Ebenda, S. 112-121.

198 Zwei Verbalnoten der Botschaft der Polnischen Republik vom 15.11. und 24.11.1938 zum Mord an Chaim Both finden sich in den Akten der Reichskanzlei, BArch, R 43 II, 599b, Fiche 1 von 4, Bl. 12-13, 22.

199 Vermerk aus den Akten des A.A. für Ribbentrop, 16.12.1938, BArch, R 43 II, 599b, Fiche 1 von $4, \mathrm{Bl} .30$.

200 Meyer, „Arisiert“ und ausgeplündert, S. 83; Friedländer, Das Dritte Reich und die Juden, Bd.I, S. 294. 
„Wächter meldet mir, Befehl ausgeführt“ (TG, 10.11.1938). Die Berliner Hauptsynagoge wurde jedoch nicht nur „zerschlagen“ (TG, 10.11.1938), wie Goebbels zunächst wohl angeordnet hatte, sondern „von der SA angezündet“. ${ }^{201}$ Daß sich bei dem Pogrom insbesondere die Gau- und Gaupropagandaleiter durch Befehle hervortaten, ist seit langem bekannt. ${ }^{202}$ Aber daß Goebbels die Zerstörung der Hauptsynagoge als seine persönliche Aufgabe begriff und sie befahl, ist eine der vielen neuen Erkenntnisse, die erst durch die Goebbels-Tagebücher gewonnen werden konnten. ${ }^{203}$

Die Verordnungen, die infolge des Pogroms erlassen wurden, waren schwerwiegend. Auch sie gingen, wie aus Goebbels' Tagebuch ersichtlich wird, auf Hitler zurück. Am 10. November 1938, als in zahlreichen Städten das Zerstören, Brandschatzen und Morden fortgesetzt wurde, und Goebbels Hitler Bericht erstattete, äußerte sich Hitler bereits über neue Maßnahmen gegen die jüdische Bevölkerung: „Der Führer will zu sehr scharfen Maßnahmen gegen die Juden schreiten. Sie müssen ihre Geschäfte selbst wieder in Ordnung bringen. Die Versicherungen zahlen ihnen nichts. Dann will der Führer die jüdischen Geschäfte allmählich enteignen und den Inhabern dafür Papiere geben, die wir jederzeit entwerten können. Im Übrigen hilft sich das Land da schon durch eigene Aktionen. Ich gebe entsprechende Geheimerlasse ${ }^{204}$ heraus“ (TG, 11.11.1938). Einige dieser Vorstellungen Hitlers wurden zwei Tage später, nach der „Besprechung über die Judenfrage“ im Reichsluftfahrtministerium, Gesetz. Ganz offensichtlich hatte Göring, der sich zu Beginn dieser Tagung auf einen Brief von Martin Bormann „im Auftrag des Führers“ berief, ${ }^{205}$ Weisungen von Hitler erhalten. In der von Göring erlassenen „Verordnung zur Wiederherstellung des Straßenbildes bei jüdischen Gewerbebetrieben“ war festgelegt, daß Juden die Schäden an ihren Geschäften oder Wohnungen sofort zu beseitigen, die Kosten dafür selbst zu tragen hatten und etwaige Versicherungsansprüche dem Deutschen Reich verfielen. ${ }^{206}$ Es war also nicht „Görings Wunsch“, daß die geschädigten Juden von ihren Versicherungen

201 Gruner, Judenverfolgung in Berlin, S.59; siehe auch Kellerhoff, „Kristallnacht“, S.21f.

202 Goebbels hielt zur Aktivität der Gauleiter fest: „Alle Gauleiter haben tabula rasa gemacht“, TG, 12.11.1938. Vgl. z. B. Kropat, „Reichskristallnacht“, S. 113; Graml, Reichskristallnacht, S.20-25; Adam, Wie spontan, S.79; Friedländer, Das Dritte Reich und die Juden, Bd.I, S. 295.

203 Bis zur Veröffentlichung dieser Tagebuchpassage war davon ausgegangen worden, Goebbels selbst sei über indirekte Appelle zum Handeln nicht hinausgegangen; so z.B. Graml, Reichskristallnacht, S.25. Friedländer, Das Dritte Reich und die Juden, Bd.I, S.294, wies als erster auf diese bedeutende Textstelle des Goebbels-Tagebuchs hin.

${ }^{204}$ Hiermit meinte Goebbels die im Reichsgesetzblatt nicht veröffentlichte Anordnung des Präsidenten der Reichskulturkammer vom 12.11.1938, die Juden den Besuch von Theatern, Kinos, Ausstellungen, Konzerten etc. untersagte; abgedr. in: Walk, Sonderrecht, S.255. Den Vorteil von derartigen Erlassen gegenüber Gesetzen notierte Goebbels ein Jahr zuvor: „Die Juden setzen wir durch Polizeiverordnungen aus den Kulturveranstaltungen heraus. Ein Gesetz würde zuviel Aufsehen erregen“, TG, 3.12.1937.

205 Stenographische Niederschrift der Besprechung über die Judenfrage bei Göring, 12.11.1938, in: IMG 28, Dok. 1816-PS, S. 499; VEJ, Bd.2, Dok. 146, S. 408.

206 Verordnung zur Wiederherstellung des Straßenbildes bei jüdischen Gewerbebetrieben, 12.11.1938, RGBl.1938, Teil I, S.1581. 
keine Mark sehen sollten, wie Kropat in Unkenntnis dieser Tagebuchpassage von Goebbels schrieb, sondern Hitlers Idee, ${ }^{207}$ die dahingehend modifiziert wurde, daß die „Versicherungsansprüche von Juden deutscher Staatsangehörigkeit [...] zugunsten des Reiches beschlagnahmt" wurden, ${ }^{208}$ um der deutschen Versicherungswirtschaft etwaige devisenbringende Rückversicherungsleistungen aus dem Ausland zu ermöglichen. Die vollständige Enteignung jüdischer Unternehmen, die Hitler beabsichtigte, zog sich zwar noch etwas hin, aber die Entfernung der Juden aus dem Wirtschaftsleben wurde durch eine weitere Verordnung Görings vom 12. November entscheidend vorangetrieben. Sie bestimmte, daß Juden zum 1. Januar 1939 der Betrieb von Einzelhandel- oder Versandgeschäften, die selbständige Ausübung eines Handwerks, der Handel auf Märkten und Messen und die Leitung eines Unternehmens verboten wurden. ${ }^{209}$ Damit war für Juden beinahe ein vollständiges Gewerbeverbot ausgesprochen und der Wunsch Hitlers verwirklicht, der jüdischen gewerbetreibenden Bevölkerung endgültig ihre Existenzgrundlage zu entziehen. Auch die dritte Verordnung des Beauftragten für den Vierjahresplan von diesem Tag, die Juden eine „Sühneleistung“ von einer Milliarde Reichsmark auferlegte, ${ }^{210}$ ging auf eine Idee Hitlers zurück. ${ }^{211}$

Bei der erwähnten „Besprechung über die Judenfrage“ bei Göring am 12. November war auch Goebbels anwesend. Das, was er darüber notierte, entspricht genau dem, was dort der Niederschrift zufolge behandelt wurde und sich später in Form der genannten Verordnungen niederschlug: „Konferenz bei Göring über die Judenfrage. [...] Ergebnis: die Juden bekommen eine Kontribution von einer Milliarde auferlegt. Sie werden in kürzester Frist gänzlich aus dem wirtschaftlichen Leben ausgeschieden. Sie können keine Geschäfte mehr betreiben. Bekommen dafür nur Schuldbuchverschreibungen zu 3\%. Die Schäden müssen sie selbst decken. Versicherungsbeträge verfallen dem Staate“ (TG, 13.11.1938). Zu seiner eigenen Rolle hielt Goebbels fest: „Ich vertrete einen radikalen Standpunkt“ (TG, 13.11.1938). Auch diese Selbsteinschätzung stimmte, denn Goebbels plädierte bei dieser Besprechung dafür, daß Juden besondere Abteile in Zügen zugewiesen werden sollten, daß Juden verboten werden sollte, die allgemeinen Bäder, Erholungsstätten, Parkanlagen und Wälder zu betreten und öffentliche Kinos, Theater und Schulen zu besuchen. ${ }^{212}$ Den Entwurf für einen Erlaß zur Entfernung

207 Kropat, „Reichskristallnacht“, S. 128.

208 Verordnung zur Wiederherstellung des Straßenbildes bei jüdischen Gewerbebetrieben, 12.11.1938, RGBl. 1938, Teil I, S.1581; vgl. auch die der Verordnung vorausgehende Debatte bei Göring, Stenographische Niederschrift der Besprechung über die Judenfrage im Reichsluftfahrtministerium, 12.11.1938, in: IMG 28, Dok. 1816-PS, S.500, 511-521; VEJ, Bd.2, Dok. 146, S.409f., 417-424. Zu den weiteren antijüdischen Maßnahmen bis Ende 1938, die z.T. Gegenstand dieser Besprechung waren, siehe Friedländer, Das Dritte Reich und die Juden, Bd.I, S.302-314; Döscher, „Reichskristallnacht“, S. 123-127.

${ }^{209}$ I. Verordnung Zur Ausschaltung der Juden aus dem deutschen Wirtschaftsleben, 12.11.1938, RGBl.1938, Teil I, S.1580.

210 Verordnung über eine Sühneleistung der Juden deutscher Staatsangehörigkeit, 12.11.1938, RGBl.1938, Teil I, S. 1579.

211 Graml, Reichskristallnacht, S. 178.

212 Stenographische Niederschrift der Besprechung über die Judenfrage bei Göring, 12.11.1938, in: IMG 28, Dok. 1816-PS, S.509-511; VEJ, Bd.2, Dok. 146, S.415-417. 
der Juden aus Theatern und Kinos hatte Goebbels bereits am Vortag erarbeitet: „Mit Hinkel lege ich eine Verordnung fest, daß die Juden keine Theater und Kinos mehr besuchen dürfen" (TG, 12.11.1938). Am Tag der Konferenz trat diese Verordnung in Kraft. ${ }^{213}$ Drei Tage später wurde auch das Verbot für jüdische Kinder erlassen, öffentliche Schulen zu besuchen. ${ }^{214}$

In Berlin waren die Nachwirkungen des Pogroms für die jüdische Bevölkerung noch um einiges schlimmer als im übrigen Reichsgebiet. Zunächst, unabhängig und noch vor der reichsweiten Verordnung über die „Sühneleistung“, wurde den Berliner Juden von ihrem Gaupropagandaleiter Werner Wächter - sicher nicht ohne Zustimmung Goebbels' - eine Zwangsabgabe in Höhe von fünf Millionen RM auferlegt. Im Sprachgebrauch der Berliner Nationalsozialisten handelte es sich hierbei um eine „freiwillige Spende“ als „Wiedergutmachung der Glasschäden Berlins“, die in den sogenannten Scherbenfonds floß, aus dem das Staatsbegräbnis Raths finanziert wurde und die Berliner NSDAP-, SA- und SS-Formationen für ihren, wie es hieß, „tagelangen Einsatz, auch nachts“, große Summen erhielten. ${ }^{215}$ Goebbels hielt über diese Sonderabgabe für Berliner Juden in seinem Tagebuch fest: „In Berlin ist in der Nacht alles ruhig geblieben. Die Juden haben sich bereiterklärt, für die Schäden der Tumulte aufzukommen. Das macht in Berlin allein 5 Millionen Mk. Das ist ein guter Aderlaß“ (TG, 12.11.1938). Zwei Wochen später nannte Goebbels in seinem Tagebuch auch, wer die Gelder der Berliner Juden eintrieb, was er in der ersten Notiz nicht getan hatte: „Wächter hat die Berliner Juden sehr geschröpft. Mehr Geld hereingenommen als gebraucht wird. Der Rest geht in die Hände des Reiches“ (TG, 23.11.1938). Dieses Notat von Goebbels deutet darauf hin, daß Wächter nicht eigenmächtig gehandelt hatte, sondern im Auftrag Goebbels', der den Juden offensichtlich soviel Geld abnehmen wollte, wie für die Bezahlung von Begräbnis und Tätern „gebraucht“ wurde. Be-

213 Anordnung des Präsidenten der Reichskulturkammer, 12.11.1938, in: Walk, Sonderrecht, S.255. „Ich gebe Verordnung heraus, daß Juden Besuch von Kinos und Theatern verboten ist. Das war notwendig und zweckmäßig", TG, 13.11.1938. Eine solche Verordnung war schon lange geplant worden, denn bereits Ende 1937 hielt Goebbels fest: „Führer gibt mir Auftrag [...] zu einem Gesetzentwurf, daß Juden keine deutschen Theater- und Kulturveranstaltungen mehr besuchen dürfen“, TG, 26.11.1937; vgl. auch TG, 3. 12.1937, zit. auf S. 350, Anm. 204 dieser Studie.

214 Erlaß des Reichsministeriums für Wissenschaft, Erziehung und Volksbildung, 15.11.1939, in: Walk, Sonderrecht, S.256. Bei der Notiz über den Erlaß Bernhard Rusts beging Goebbels allerdings einen Fehler, denn er hielt fest: „Rust verbietet den Juden das Studium an den Universitäten“, TG, 15.11.1938. Tatsächlich betraf dieses Verbot jedoch die jüdischen Schülerinnen und Schüler; das Verbot, Universitäten zu besuchen, erfolgte am 8.12.1938; vgl. Metzger, Kristallnacht, S. 12.

215 Vgl. Meyer, „Arisiert“ und ausgeplündert, S. 83, 87, Anm.26, 29, die sich auf einen Aufsatz von Hans-Erich Fabian beruft, der am 8.11.1946 in der Zeitschrift „Der Weg. Zeitschrift für Fragen des Judentums“ erschien. Wegen der hohen Summe, die innerhalb weniger Tage aufgetrieben wurde, und Belegen, daß zwei Angehörige einer jüdischen Unternehmerfamilie am 19.11.1938 allein 850000 RM zahlen mußten, dürfte zu schließen sein, daß sich der Spendenfonds vor allem aus Geldern von Geschäftsleuten zusammengesetzt hat. Wie diese Erpressungen vollzogen wurden, schrieb die Autorin nicht und scheint noch unerforscht. In den einschlägigen Werken zum Novemberpogrom findet sich zumeist nicht einmal ein Hinweis auf die Berliner Sonderabgabe. 
reits am 10. November, nach dem Gespräch mit Hitler, hatte Goebbels in sein Tagebuch geschrieben: „Die Juden sind am Ende doch sehr dumm. Und sie müssen ihre eigenen Fehler teuer bezahlen" (TG, 11.11.1938). Goebbels sah in dem Attentat des verzweifelten Heranwachsenden Grynszpan also offenbar eine Aktion des „Weltjudentums“, welches die Kosten-Nutzen-Bilanz des Anschlags falsch eingeschätzt habe, da es mit einer solchen Reaktion des NS-Regimes nicht gerechnet habe. Es ist wahrscheinlich, daß Goebbels das Vorgehen in Berlin am 10. November mit Hitler, den er mittags und abends traf, abgestimmt hatte. Es war noch vor Görings Verordnung über die „Sühneleistung“ und Goebbels’ Rückkehr nach Berlin beschlossen worden.

„In Berlin tuen [!] wir mehr als im übrigen Reich. Das ist auch nötig, weil hier so viele Juden sitzen“, (TG, 22.11.1938) schrieb Goebbels zwei Wochen nach dem Pogrom in sein Tagebuch. Vom Ehrgeiz besessen, eine Vorreiter-Rolle zu spielen, überlegte Goebbels mit dem Berliner Polizeipräsidenten Helldorf weitere antijüdische Maßnahmen, wie schon im Frühjahr 1938: „Helldorff [!] verbietet den Juden in Berlin bestimmte Straßen und Stadtviertel. Der Judenbann ist da" (TG, 4.12.1938), hielt Goebbels über die Anordnung Helldorfs vom 3. Dezember 1938 fest. Diese untersagte Juden die Begehung bestimmter Zonen im Bereich der Wilhelmstraße, der Voßstraße und Unter den Linden sowie den Besuch von Kulturveranstaltungen, Museen, Sportplätzen, Badeanstalten, Ausstellungen etc. ${ }^{216}$ Offenbar hatten Goebbels und Helldorf bereits angeregt, diese Anordnung sogleich auf das Reich zu übertragen, was Hitler Goebbels zufolge allerdings abgelehnt habe: „Gestern: der Führer ist mit dem von Helldorff [!] verkündeten Judenbann nicht einverstanden. Jedenfalls soll er nicht über Berlin hinaus ausgedehnt werden“ (TG, 6.12.1938). Die „Judenpolitik“, das zeigt sich mehr und mehr, war im Dritten Reich dem „Führer" vorbehalten.

Aber auch auf Reichsebene hatten die Entrechtung und Verfolgung der Juden schlagartig zugenommen. Neben den zahlreichen Bestimmungen zur Ausschaltung der Juden aus dem Wirtschaftsleben und den sogenannten Sühneleistungen für den Mord an vom Rath erwähnte Goebbels bis Ende 1938 noch einige weitere antijüdische Maßnahmen. „Die Juden dürfen am Samstag, dem ,Tag der nationalen Solidarität' ihre Häuser nicht verlassen“ (TG,30.11.1938), schrieb Goebbels korrekt über eine Anordnung Himmlers zum 3. Dezember 1938. ${ }^{217}$ Im Tagebucheintrag über den „Tag der Nationalen Solidarität“ notierte Goebbels: „Himmler entzieht ihnen [den Juden, d.V.] die Erlaubnis, Kraftfahrzeuge zu halten. So geht eins nach dem andern. Wir werden nicht locker lassen, bis wir sie heraushaben" (TG, 4.12.1938). ${ }^{218}$ Die Vertreibung der jüdischen Bevölkerung wurde nun noch stärker forciert. Andere innenpolitische Fragen wie beispielsweise die Auseinan-

216 Vgl. Gruner, Judenverfolgung in Berlin, S.60; Walk, Sonderrecht, S. 262.

217 Anordnung des RFSSuCdDP, 29.11.1938; Anordnung des Chefs der Sicherheitspolizei, 2.12.1938, in: Walk, Sonderrecht, S.260f.

218 Erlaß des RFSSuCdDP, 3.12.1938, in: Ebenda, S.262. 
dersetzung mit den christlichen Kirchen mußten demgegenüber, wie Goebbels überliefert, zurückgestellt werden. ${ }^{219}$

Auch vor ausländischen Regierungsmitgliedern brachte Hitler seinen „Entschluß“ deutlich zum Ausdruck, das Judentum im Reichsgebiet auszulöschen. ${ }^{220}$ Gegenüber dem tschecho-slowakischen Außenminister František Chvalkovský äußerte Hitler dem Gesprächsprotokoll zufolge, welches alles in indirekter Rede im Konjunktiv wiedergibt: „Die Juden würden bei uns vernichtet.“221 Damit brachte Hitler schon vor seiner berüchtigten Reichstagsrede vom 30. Januar 1939 und bedingungslos zum Ausdruck, daß er die Auslöschung des Judentums in Deutschland beabsichtigte. In der Reichstagsrede hatte Hitler die „Vernichtung der jüdischen Rasse in Europa“ für den Fall vorausgesagt, daß es „dem internationalen Finanzjudentum inner- und außerhalb Europas gelingen sollte, die Völker noch einmal in einen Weltkrieg zu stürzen".222 Goebbels, der die Rede im Reichstag mitverfolgt hatte und „ganz hingerissen“ (TG, 31.1.1939) war, erwähnte diese Androhung der Vernichtung des Judentums nicht in seinem Tagebuch, möglicherweise hielt er sie für phantasievolles Drohgeschwätz. Während des Krieges jedoch, als ihn nach und nach Informationen über den Massenmord am jüdischen Volk erreichten, bezog er sich immer wieder auf diese Rede und notierte, daß sich die Prophezeiung Hitlers nun erfülle. ${ }^{223}$

\section{Die Goebbels-Tagebücher als Quelle für die Geschichte des Novemberpogroms}

\section{Die Rolle Hitlers}

Alle wesentlichen antisemitischen Maßnahmen bis November 1938 und auch Verbote antijüdischer Ausschreitungen, wie im Jahre 1936, als Tausende ausländischer Gäste die olympischen Winter- und Sommerspiele in Deutschland besuchten, gingen auf eine Entscheidung Hitlers zurück oder fanden zumindest seine $\mathrm{Zu}$ stimmung. Viele folgenschwere Gesetze und Verordnungen gegen die jüdische Bevölkerung trugen Hitlers Unterschrift. ${ }^{224}$ Auch billigte Hitler im Jahre 1938 alle

219 „Kerrl will einen neuen Streit in der Kirche anfangen. Den können wir aber jetzt nicht gebrauchen. Erst muß die Judenfrage durchgepaukt werden“, TG, 30.11.1938; „Kerrl macht wieder lauter Dummheiten. Faselt von einer neuen evangelischen Synode. Er hat ein seltenes Talent, die Dinge, sobald sie sich etwas beruhigt haben, wieder anzurühren. Der Führer gibt ihm den Befehl, abzustoppen. Wir werden jetzt zuerst einmal die Judenfrage lösen“, TG, 8.12.1938.

220 Aufzeichnung über Unterredung Hitlers mit Józef Beck, 5.1.1939, in: ADAP, D 5, Dok. 119, S.130f.

221 Aufzeichnung über Unterredung Hitlers mit Chvalkovský, 21.1.1939, in: ADAP, D 4, Dok. 158, S. 170 .

222 Reichstagsrede Hitlers, 30.1.1939, in: Verhandlungen des Reichstags, Bd.460, S. 16.

223 Vgl. TG, 20.6.1941, 11.8.1941, 19.8.1941, 13.12.1941, 27.3.1942, 29.4.1942, 14.12.1942, 3.1.1943, 11.4.1943.

224 Beispielsweise das "Gesetz zur Wiederherstellung des Berufsbeamtentums" vom 7.4.1933, das „Gesetz gegen jüdische Rechtsanwälte“ vom 7.4.1933, das „Gesetz gegen 
von Goebbels vorgeschlagenen und äußerst brutalen Maßnahmen gegen die Juden in Berlin. Erscheint es angesichts einer so „konsequent“ antisemitischen Politik des „Führers“ glaubwürdig, wenn einige Adjutanten und Mitarbeiter Hitlers oder SS-Führer nach dem Krieg behaupteten, Hitler sei über den Novemberpogrom überrascht oder entsetzt gewesen?225 Derartige Aussagen sind allein schon durch den Bericht des Obersten Parteigerichts der NSDAP zu widerlegen. Ausdrücklich heißt es darin, Hitler habe, nachdem er von Goebbels über die Ausschreitungen in Kurhessen und Magdeburg-Anhalt informiert worden war, „auf seinen [Goebbels, d.V.] Vortrag entschieden“, daß derartigen Demonstrationen „nicht entgegenzutreten“ sei. ${ }^{226}$ Die Goebbels-Tagebücher bestätigen die Annahme, Hitler habe die Ausschreitungen nicht verhindern wollen. Sie belegen sogar, daß Hitler eine Fortsetzung und Ausweitung der Gewalt befahl: „Ich trage dem Führer vor. Er bestimmt: Demonstrationen weiterlaufen lassen. Polizei zurückziehen. Die Juden sollen einmal den Volkszorn zu verspüren bekommen“" (TG, 10.11. 1938). Darüber hinaus geht aus den Tagebüchern aber auch hervor, daß Hitler von Goebbels eine Vollzugsmeldung einforderte und im nachhinein sehr zufrieden über den Pogrom war (TG, 11.11.1938). Ferner belegen die Goebbels-Tagebücher, daß die Verhaftung der ca. 30000 Juden von Hitler veranlaßt wurde (TG, 10.11.1938) und er bereits am Mittag nach der Pogromnacht weitere Schritte in Richtung einer Vernichtung der jüdischen wirtschaftlichen Existenzen plante (TG, 11.11.1938), von denen Goebbels (TG, 12.11.1938) und Göring (TG, 13.11. 1938) einige sofort in die Tat umsetzten. Eine Idee Hitlers hingegen wurde erst Jahre später restlos verwirklicht: „Dann will der Führer die jüdischen Geschäfte allmählich enteignen und den Inhabern dafür Papiere geben, die wir jederzeit entwerten können" (TG, 11.11.1938). Hitler gab also die Befehle, nach denen das Eigentum der jüdischen Bevölkerung zerstört, die Juden verhaftet und deren übriggebliebenes Kapital eingezogen werden sollte.

Wahrscheinlich beauftragte Hitler darüber hinaus seine ältesten und treuesten Gefolgsleute, die 1923 den „Stoßtrupp Hitler“ gebildet hatten, ganz konkrete, symbolträchtige Ziele der jüdischen Bevölkerung zu zerstören. Die Notate von Goebbels in seinem Tagebuch legen nahe, daß Mitglieder dieses Traditionsverbandes die Ohel-Jakob-Synagoge in der Herzog-Rudolf-Straße in München verwüstet und in Brand gesteckt haben (TG, 10.11.1938). Daß diese „alten Kämpfer“ losgezogen wären, ohne sich zuvor Hitlers Rückendeckung zu versichern, ist undenkbar. Die Rolle des „Stoßtrupps Hitler“ bei der Reichspogromnacht bedarf weiterer Erforschung. Gründe für dieses Forschungsdefizit könnten sein, daß dieser Verband nach 1924 als nicht mehr existent galt, daß er im Zusammenhang mit den antisemitischen Ausschreitungen in keiner anderen Quelle genannt wird und daß bisher davon ausgegangen wurde, all die Versammlungsteilnehmer hätten pro-

die Überfüllung deutscher Schulen und Hochschulen“ vom 25.4.1933, das „Reichserbhofgesetz" vom 29.9.1933, das "Schriftleitergesetz" vom 4.10.1933, das „Reichsbürgergesetz" und das "Gesetz zum Schutze des deutschen Blutes und der deutschen Ehre“, beide vom 15.9.1935, und die vielen Nachfolgeverordnungen zum Reichsbürgergesetz.

225 Siehe hierzu Kershaw, Hitler, Bd.2, S. 209 und S. 1130f., Anm. 110-115.

226 Bericht des Obersten Parteigerichts an Göring vom 13.2.1939, in: IMG 32, Dok.3063PS, S.21. 
grammgemäß ${ }^{227}$ an der Vereidigung der SS-Rekruten am Odeonsplatz zwischen Mitternacht und 1 Uhr morgens teilgenommen - in der Zeit, in der die Synagoge angezündet wurde. Daß Goebbels diese Truppe viermal erwähnte, während er über die Rolle der SA gar nichts notierte, verweist auf die Bedeutung der „alten Kämpfer" für die antijüdische Gewalt in München.

\section{Goebbels' Antisemitismus}

Joseph Goebbels war keineswegs Antisemit aus „Opportunismus“,228 wie lange Zeit angenommen wurde. ${ }^{229}$ Claus-Ekkehard Bärsch und Ulrich Höver haben auf der Basis der Goebbels-Tagebücher nachgewiesen, daß Goebbels längst einen radikalen Judenhaß entwickelt hatte, ehe er im Frühjahr 1925 zur NSDAP stieß.230 Bereits vor 1933 hatte Goebbels sich intensiv damit beschäftigt, wie die sich ihm stellende „Judenfrage“ zu lösen wäre. In den Umkreis seiner Erwägungen gehörten der Ausschluß der Juden aus dem öffentlichen Leben, die Vertreibung der Juden aus Deutschland, antisemitische Pogrome und eine vage formulierte, als Andeutung der Vernichtung zu interpretierende „Beseitigung“ der Juden überhaupt. ${ }^{231}$ Als David Frankfurter am 4. Februar 1936 den NSDAP-Landesleiter in der Schweiz, Wilhelm Gustloff, erschossen hatte, wollte Goebbels antisemitische Ausschreitungen organisieren. Er hatte im Anschluß an die Todesnachricht in sein Tagebuch notiert: „Das wird den Juden teuer zu stehen kommen. Wir machen größere Aktionen dagegen“ (TG, 6.2.1936). Nach einer Unterredung zwischen Goebbels und Hitler blieb damals angesichts der zwei Tage später von Hitler zu eröffnenden olympischen Winterspiele ein Pogrom aus. Aber der Gedanke daran war auch 1936 vorhanden. Bei der Lektüre von Emil Ludwigs „Der Mord in Davos“ notierte Joseph Goebbels den Wunsch in sein Tagebuch, das Judentum zu vernichten: „Da kann man Antisemit werden, wenn man es nicht schon wäre. Diese Judenpest muß ausradiert werden. Ganz und gar. Davon darf nichts übrig bleiben" (TG, 6.11. 1936). Die Idee, dem Mord an Gustloff 1936 antijüdische Pogrome folgen zu lassen, scheint in nationalsozialistischen Kreisen weit verbreitet gewesen zu sein. Daher sah sich der Stellvertreter des Führers veranlaßt, in einer Anordnung darauf hinzuweisen, daß „Einzelaktionen gegen Juden [...] unbedingt zu unterbleiben haben". 232

227 Auf der Einladungskarte zum „Gesellige[n] Beisammensein der Führerschaft der NSDAP“ im Festsaal des Alten Rathauses am Abend des 9.11.1938 war als Anschlußveranstaltung folgendes vorgesehen: „Anschließend Teilnahme an der Vereidigung der SS an der Feldherrnhalle“. StadtAM, Bürgermeister und Rat, Nr.458/3 (als Faksimile abgedr. in: Heusler/Weger, „Kristallnacht“, S.46).

228 So auch Höver, Goebbels, S. 148-151, 173-179, 403.

229 Heiber, Goebbels, S.315f. und S.75. Ähnlich Stephan, Goebbels, S. 184, und Fest, Gesicht, S.133f.; Fest, Portraitskizze, S. 574.

230 Vgl. Bärsch, Katastrophenbewußtsein, S.125-151, v.a. S.138-141, 145-149; Höver, Goebbels, S. 148-152.

231 Vgl. Höver, Goebbels, S. 173-179.

232 Anordnung Nr.17/36 des Stellvertreters des Führers, Rudolf Heß, 5.2.1936, streng vertraulich, an alle Reichsstatthalter, Landesregierungen, Preußischen Oberpräsidenten und Polizeibehörden, Gauleitungen. Die Gauleitungen wurden aufgefordert, „sämtli- 
Seit dem „Anschluß“ Österreichs an das Deutsche Reich verfolgte Goebbels das „ehrgeizige Ziel“, aus der Reichshauptstadt die jüdische Bevölkerung ähnlich rasch zu verdrängen, wie es Hitler in Wien zu tun beabsichtigte. Die antisemitischen Maßnahmen, die Goebbels zusammen mit Helldorf in der Folgezeit für Berlin ersann und die im Mai 1938 in einer Denkschrift zusammengefaßt wurden, beinhalteten viele der radikalen Forderungen, die Goebbels auf der „Besprechung über die Judenfrage“ am 12. November 1938 wiederholte, beispielsweise, Juden den Zutritt zu Parkanlagen zu verwehren oder Juden besondere Abteile in Zügen zuzuteilen. ${ }^{233}$ Bereits im Frühsommer 1938 hatte Goebbels in Berlin nach Absprache mit Hitler Tausende von Juden verhaften und in Konzentrationslager einliefern lassen. Damals schon waren in Berlin parallel zu den Festnahmen jüdische Geschäfte und Synagogen beschädigt worden, und jüdischen Ladenbesitzern hatte man auferlegt, daß sie „ihre Geschäfte wieder selbst säubern“ sollten (TG, 22.6.1938). Zu Recht hatte Saul Friedländer die Berliner Ereignisse als „Probe im kleinen Rahmen“ bezeichnet. ${ }^{234}$ Ab Juli 1938 wandte der Berliner Polizeipräsident Helldorf im Einvernehmen mit Goebbels die „Richtlinien für die Behandlung von Juden und Judenangelegenheiten“ in der Reichshauptstadt an, die keinen anderen Zweck hatten, als die jüdische Bevölkerung zu schikanieren. Goebbels’ Antisemitismus hatte also bereits im Sommer 1938 die Schwelle überschritten, die als „Rückfall in die Barbarei“ 235 bezeichnet wurde.

Es bedurfte keiner Baarova-Affäre, um bei Goebbels die Bereitschaft zu schaffen, mit brutalen, terroristischen Methoden gegen die jüdische Minderheit vorzugehen. Das von Hitler erzwungene Ende von Goebbels' Affäre mit der tschechischen Schauspielerin Lida Baarova im Herbst 1938 spielt für die Novemberpogrome nicht die geringste Rolle. ${ }^{236}$ In den Tagebüchern von Goebbels findet sich kein einziger Hinweis darauf, daß Goebbels das Gefühl gehabt habe, er müsse sich bei Hitler rehabilitieren, da er im Vorfeld des geplanten Angriffs auf die Tschechoslowakei ausgerechnet mit einer Tschechin liiert war. Auch die neuerdings von Peter Longerich vertretene These, Goebbels habe wegen seiner von Hitler abweichenden Auffassung auf dem Höhepunkt der Sudetenkrise nun in der „Judenfrage" Gewaltbereitschaft demonstrieren wollen, wird durch die Tagebücher nicht gestützt. ${ }^{237}$ Goebbels war Antisemit „aus Instinkt und aus Verstand“, wie er bereits im Frühjahr 1924 im Tagebuch festhielt (TG, 10.4.1924). Daher wollte er auch gleich nach dem Mord an Wilhelm Gustloff „größere Aktionen“ gegen das Juden-

chen untergeordneten Parteidienststellen sofort telefonisch oder telegraphisch den Inhalt dieses Runderlasses zur Kenntnis zu geben“. Österreichisches Staatsarchiv, AdR, 04: Inneres/Justiz, Reichskommissar für die Wiedervereinigung Österreichs mit dem Deutschen Reich, Bürckel/Materie, Mappe 4210, Karton 192.

233 Gruner, Denkschrift, S.334, 336; Stenographische Niederschrift der Besprechung über die Judenfrage bei Göring, 12.11.1938, in: IMG 28, Dok. 1816-PS, S.509-511; VEJ, Bd.2, Dok. 146, S. 415-417.

${ }^{234}$ Friedländer, Das Dritte Reich und die Juden, Bd.I, S. 284.

235 Benz, Rückfall in die Barbarei, S. 13.

236 Die gegenteilige These vertreten u.a. Heiber, Goebbels, S.280; Graml, Reichskristallnacht, S. 176; Adam, Wie spontan, S.91; Meissner, Magda Goebbels, S.235; Longerich, Goebbels, S.394; und Kershaw, Hitler, Bd.2, S. 205.

237 Longerich, Goebbels, S. 394, 396f. 
tum beginnen (TG, 6.2.1936), die infolge der stattfindenden olympischen Winterspiele in Garmisch-Partenkirchen ausblieben. Außerdem hatte Goebbels durch seine erwähnten Aktionen im Frühsommer 1938 in Berlin bewiesen, daß ihm Pogrome grundsätzlich als geeignetes Mittel erschienen, um die jüdische Bevölkerung aus dem Reich zu vertreiben. Schon Tage vor dem Grynszpan-Attentat war Hitler zu Goebbels, wie dieser vermerkte, „besonders nett“ (TG, 5.11.1938). Die Baarova-Affäre steht also in keinem Zusammenhang mit der Hetzrede von Goebbels am 9. November 1938, denn Goebbels hätte jederzeit auf Anweisung Hitlers oder bei seiner Billigung Pogrome in Gang gesetzt, die auch ihm, besonders in Berlin, ureigenes Anliegen waren.

\section{Zum Zweck des Pogroms}

Die Tagebücher von Joseph Goebbels ermöglichen die Klärung der Urheberschaft des Pogroms und die Benennung einiger Anstifter und Täter. Daneben liefern sie auch konkrete Hinweise auf die Motivation für die Pogrome: Die Anfang 1933 einsetzende, schrittweise Entrechtung der Juden im Dritten Reich und die antisemitischen Ausschreitungen führten zu immer neuen Emigrationswellen der in Deutschland lebenden Juden. Als gegen Ende des Jahres 1937 die Zahl der jüdischen Emigranten stagnierte, sich die potentiellen Einwanderungsländer im Juli 1938 auf einer Konferenz in Evian dagegen wehrten, die Immigrationsquoten für Juden zu erhöhen, waren sich die zuständigen Behörden wie Gestapo und SD des Scheiterns der bisherigen „Judenpolitik“ bewußt. ${ }^{238}$ Möglicherweise besann sich die NS-Führung deshalb Anfang November 1938 auf ein Memorandum „Zum Judenproblem“ von 1937, das von Adolf Eichmann als Experte der jüdischen „Auswanderung“ verfaßt worden war. „Das wirksamste Mittel“ zur „Entjudung Deutschlands“, so hieß es dort, sei „der Volkszorn“, da „der Jude [...] nichts so fürchtet als eine feindliche Stimmung, die sich jederzeit spontan gegen ihn wenden kann".239 Lange vor und einige Zeit nach dem Novemberpogrom war die Vertreibung der Juden aus dem Deutschen Reich das Hauptziel nationalsozialistischer „Judenpolitik“. ${ }^{240}$ Drei Tage nach dem Pogrom erläuterte Reinhard Heydrich auf der Konferenz bei Göring, das „Grundproblem“ bestehe darin, die Juden aus Deutschland herauszubekommen und dies sei durch die Entfernung der Juden aus dem Wirtschaftsleben nicht zu lösen. ${ }^{241}$ Auch in den Goebbels-Tagebüchern finden sich zahlreiche Belege dafür, daß die antisemitischen Maßnahmen in erster Linie dem Zweck dienten, die jüdische Minderheit aus dem Staat zu treiben. Ende November 1937 hatten Goebbels und Hitler über die Vertreibung der Juden gesprochen, wobei Hitler sich „entschlossen“ zeigte, die Juden „aus Deutschland, ja

238 Vgl. Wildt, Judenpolitik des SD, S.57f.; Longerich, Politik, S. 134, 170; Herbert, Best, S.214; Kropat, „Reichskristallnacht“, S.27; zur Konferenz von Evian siehe Kieffer, Judenverfolgung, S. 155-324.

239 Memorandum „Zum Judenproblem“, Januar 1937, vermutlich von Adolf Eichmann verfaßt, in: Wildt, Judenpolitik des SD, Dok. 9, S.96, 99.

240 So auch Longerich, Befehl, S. 57, 70.

241 Stenographische Niederschrift der Besprechung über die Judenfrage bei Göring am 12.11.1938, in: IMG 28, Dok. 1816-PS, S.532; VEJ, Bd.2, Dok. 146, S. 431. 
aus ganz Europa“ zu entfernen (TG,30.11.1937). Im Frühsommer 1938 hatte Goebbels mit Zustimmung Hitlers und in Zusammenarbeit mit Helldorf in Berlin versucht, durch besonders schikanöse Maßnahmen die Reichshauptstadt ethnisch zu säubern, also „judenrein“ (TG, 19.6.1938) zu machen. ${ }^{242}$ Während der „JuniAktion“ in Berlin notierte Goebbels: „Nicht Gesetz ist die Parole sondern Schikane. Die Juden müssen aus Berlin heraus“ (TG, 11.6.1938). Über die 76 schikanösen „Richtlinien für die Behandlung von Juden und Judenangelegenheiten“, die Helldorf im Juli 1938 für Berlin ausarbeiten ließ, hielt Goebbels fest: „Die sind nun wirklich rigoros und umfassend. Auf diese Weise treiben wir die Juden in absehbarer Zeit aus Berlin heraus“ (TG,27.7.1938). Vier Wochen vor dem Pogrom ließ sich Goebbels von Helldorf über die Fortführung der „Judenaktion“ in Berlin berichten und erfuhr, daß die Juden „nun allmählich“ Berlin verließen (TG, 12.10.1938). Am Morgen nach der Reichskristallnacht, als Goebbels die von Hitler angeordnete Verhaftung von „25-30000 Juden“ in sein Tagebuch notierte, fügte er hinzu: „Das wird ziehen. Sie sollen sehen, daß nun das Maß unserer Geduld erschöpft ist" (TG, 10.11.1938). Dem Ziel der Vertreibung entsprechend wurden die Festgenommenen auch nur gegen die Erklärung freigelassen, das Reichsgebiet binnen kurzer Frist zu verlassen. ${ }^{243}$ Auch nach dem Pogrom notierte Goebbels mehrmals in sein Tagebuch, daß das Ziel der antijüdischen Politik in der Entfernung der Juden aus dem Reich bestand: „Wir werden nicht locker lassen, bis wir sie heraushaben“, schrieb Goebbels am Tag nach der Verkündung des „Judenbanns“ um das Berliner Regierungsviertel am 3.Dezember 1938 (TG, 4. 12.1938).

Neben diesem Hauptmotiv der Vertreibung überliefert Goebbels jedoch noch weitere Beweggründe: Zum einen sollte Rache genommen werden für die tödlichen Schüsse auf den deutschen Diplomaten Ernst vom Rath: „Diesen feigen Mord dürfen wir nicht unbeantwortet lassen“ (TG,10.11.1938), notierte Goebbels als Parole, mit der er die Bedenken einiger Parteigenossen auszuräumen versuchte. Zum anderen nennt Goebbels das Motiv der Abschreckung vor weiteren Attentaten: „Dieser Tote kommt dem Judentum teuer zu stehen. Die lieben Juden werden es sich in Zukunft überlegen, deutsche Diplomaten so einfach niederzuknallen. / Und das war der Sinn der Übung“ (TG,10.11.1938). Nicht zuletzt aus Furcht vor etwaigen jüdischen Attentaten ließ der Berliner Polizeipräsident Helldorf „die Juden gänzlich entwaffnen“ (TG, 10.11.1938), eine Maßnahme, die bereits vor den Schüssen auf vom Rath eingeleitet worden war, und ordnete am 3. Dezember 1938 den erwähnten „Judenbann“ (TG, 4.12.1938) in Berlin an. ${ }^{244}$

Auch ließen sich mit der angeblich zutage getretenen Empörung der deutschen Bevölkerung weitere antijüdische Verordnungen begründen, so wie Göring dies

242 Vgl. Gruner, Judenverfolgung in Berlin, S. 50-53.

${ }^{243}$ Vgl. Longerich, Politik, S.206f.

244 Diese Berliner Bestimmung eines Waffenverbots für Juden wurde am 11.11.1938 durch eine Verordnung des Reichsinnenministers auf das gesamte Reichsgebiet ausgeweitet; RGBl.1938, Teil I, S. 1573; Gruner, Judenverfolgung in Berlin, S.58; Walk, Sonderrecht, S.253. Zum „Judenbann" siehe Gruner, Judenverfolgung in Berlin, S.60; Walk, Sonderrecht, S.262; Verordnung über das Auftreten der Juden in der Öffentlichkeit, 28.11. 1938, RGBl.1938, Teil I, S. 1676. 
am 12. November 1938 tat. $^{245}$ Vor allem Finanzminister Lutz Schwerin von Krosigk und Wirtschaftsminister Walther Funk hatten bislang in bezug auf die „Arisierung" der Wirtschaft und deren Tempo eine andere Position vertreten als Hitler, Göring und Goebbels. ${ }^{246}$ Daher schrieb Goebbels am Morgen nach dieser Konferenz im Reichsluftfahrtministerium in sein Tagebuch: „Die radikale Meinung hat gesiegt“ (TG, 13.11.1938). Die vom NS-Regime entfachte Gewalt der Parteigliederungen sollte also auch den Druck auf die Bürokratie erhöhen, durch weitere antijüdische Maßnahmen dem „Volkswillen“ Rechnung zu tragen. ${ }^{247}$ Die besonders rabiaten Antisemiten hofften nun auf verstärkte Berücksichtigung ihrer Vorstellungen und damit auf einen Machtgewinn. ${ }^{248}$ Auch in sozialer Hinsicht wurde die Ausschaltung des Judentums nun erheblich intensiviert, beispielsweise durch das Verbot für jüdische Kinder und Jugendliche, staatliche Schulen besuchen zu können. Goebbels hatte dieses am 12. November 1938 angeregt, nur drei Tage später wurde es Gesetz. ${ }^{249}$

Wenn diese Zielsetzung der Vertreibung der jüdischen Bevölkerung im Kontext der nationalsozialistischen Außenpolitik und der Kriegsvorbereitung betrachtet wird, erscheint sie als konsequente Umsetzung der von Hitler in „Mein Kampf dargelegten Gedanken. Darin hatte er geäußert, „daß, ehe man äußere Feinde besiegt, erst der Feind im eigenen Inneren vernichtet werden muß. [...] Sowie auch nur der Schatten einer Niederlage über ein im Innern nicht von Feinden freies Volk streicht, wird dessen Widerstandskraft zerbrechen und der Gegner endgültig Sieger werden". ${ }^{250}$ Wenige Wochen vor dem Pogrom hatte Hitler Goebbels seinen „Entschluß, einmal die Tschechei zu vernichten“, mitgeteilt (TG, 3. 10. 1938). Noch vor dem Pogrom hatte der Oberbefehlshaber der Wehrmacht die entsprechende Weisung hierzu erlassen. Noch vor der „Reichskristallnacht“ drängte Ribbentrop im Auftrag Hitlers gegenüber Warschau auf die Rückgabe Danzigs und die Einrichtung eines exterritorialen Korridors durch den Korridor nach Ostpreußen. Die Vertreibung der Juden und die damit erreichte Beseitigung vermeintlich oppositioneller Kräfte war aus nationalsozialistischer Perspektive eine Maßnahme der Kriegsvorbereitung. Zugleich dürfte der Novemberpogrom, aber dies wäre noch zu untersuchen, den besonders fanatischen Nationalsozialisten, die im September 1938 einen militärischen Konflikt erwartet hatten, als Plattform ihres Aggressionsabbaus gedient haben, gewissermaßen als Ersatzkrieg im kleinen. ${ }^{251}$ In München war Hitler demonstriert worden, daß er vorläufig von den West-

245 Stenographische Niederschrift der Besprechung über die Judenfrage bei Göring, 12.11.1938, IMG 28, Dok. 1816-PS, S.500; VEJ, Bd.2, Dok. 146, S. 409.

246 Vgl. Kieffer, Judenverfolgung, S.321.

247 Wildt, Volksgemeinschaft, 2008, S.76.

248 Vgl. Wildt, Judenpolitik des SD, S. 58.

249 Stenographische Niederschrift der Besprechung über die Judenfrage bei Göring, 12.11.1938, in: IMG 28, Dok.1816-PS, S.511; VEJ, Bd.2, Dok.146, S.417; Erlaß des Reichsministers für Wissenschaft, Erziehung und Volksbildung, 15.11.1938, in: Walk, Sonderrecht, S. 256.

250 Hitler, Mein Kampf, S. 775.

251 So auch Steinweis, Kristallnacht, S. 14; Wildt, Volksgemeinschaft, 2008, S. 82, interpretiert die Novemberpogrome „als aggressive Entladung der angespannten Kriegsfurcht“. 
mächten nichts zu befürchten hatte. Wenn diese nicht zugunsten eines bedrohten, souveränen Staates einschritten, konnte davon ausgegangen werden, daß die antijüdischen Aktionen außer einigen Protesten keine politischen Folgen haben würden. In der Tat, nur drei Wochen später verständigten sich die französische Regierung und das NS-Regime am 6. Dezember 1938 in einer gemeinsamen Erklärung auf „friedliche und gutnachbarliche Beziehungen“, eine gegenseitige Anerkennung der Grenzen und auf eine gemeinsame Beratung in interessierenden Fragen. ${ }^{252}$ 